\title{
A case-based reasoning recommender system for sustainable smart city development
}

\author{
Bokolo Anthony Jnr ${ }^{1}$ (D)
}

Received: 14 December 2019 / Accepted: 25 April 2020 / Published online: 19 May 2020

(c) The Author(s) 2020

\begin{abstract}
With the deployment of information and communication technologies (ICTs) and the needs of data and information sharing within cities, smart city aims to provide value-added services to improve citizens' quality of life. But, currently city planners/ developers are faced with inadequate contextual information on the dimensions of smart city required to achieve a sustainable society. Therefore, in achieving sustainable society, there is need for stakeholders to make strategic decisions on how to implement smart city initiatives. Besides, it is required to specify the smart city dimensions to be adopted in making cities smarter for sustainability attainment. But, only a few methods such as big data, internet of things, cloud computing, etc. have been employed to support smart city attainment. Thus, this study integrates case-based reasoning (CBR) as an artificial intelligence technique to develop a recommender system towards promoting smart city planning. CBR provides suggestions on smart city dimensions to be adopted by city planners/decision-makers in making cities smarter and sustainable. Accordingly, survey data were collected from 115 respondents to evaluate the applicability of the implemented CBR recommender system in relation to how the system provides best practice recommendations and retaining of smart city initiatives. Results from descriptive and exploratory factor analyses suggest that the developed system is applicable in supporting smart city adoption. Besides, findings from this study are expected to provide valuable insights for practitioners to develop more practical strategies and for researchers to better understand smart city dimensions.
\end{abstract}

Keywords $\mathrm{AI}$ in society $\cdot$ Case-based reasoning $\cdot$ Recommender systems $\cdot$ Sustainable society $\cdot$ Smart city dimensions

\section{Introduction}

Research and development in smart city have emerged as a response to mitigate the issue of rapid urbanization. This is evident as more than half of the world's population resides in cities, and this number is expected to increase to $70 \%$ by 2050 (Washburn et al. 2009; UN 2015). The increasing population in urban environments presents challenges such as traffic congestion, air pollution, waste management, energy usage, health concerns, etc. (Borja 2007). Thus, smart cities have emerged to mitigate the challenges caused by continuous urbanization by integrating information and communication technology (ICT)-based solutions to improve urban governance, policy development, and socioeconomic growth

Bokolo Anthony Jnr

anthony.j.bokolo@ntnu.no

1 Department of Computer Science, Norwegian University of Science and Technology NTNU, 7491 Trondheim, Norway
(Vázquez Salceda et al. 2014). Therefore, cities across the world are implementing smart city strategies to improve sustainability by deploying a wide range of ICTs to improve healthcare, transportation, education, energy, etc. while at the same time improving resource consumption (Anthony Jnr et al. 2020).

In this sense, smart cities aim to use innovative ICT solutions to manage urban challenges related to environment, people, mobility, security, economy, resource management, public health, etc. (Negre and Rosenthal-Sabroux 2014). A smart city invests in ICT to support sustainable socio-economic development, improved quality-of-life, and intelligent usage of natural resources. Smart city uses ICT as a prime enabler to improve integration of data to be transformed into useful information and knowledge intelligence for the sustainability of cities (Jnr et al. 2018). But presently, there is need to provide integrated information of smart city dimensions to enhance sustainability of a city (Jnr et al. 2020b). As the provided information can be utilized for citizens' engagement, urban planning, and 
policy development (Khan et al. 2013). Likewise, previous approaches lack the capability to provide contextual information on smart city dimensions to be adopted by cities to be more innovative, productive, and be able to make decisions which impact on their well-being, environmental and economic sustainability (Khan et al. 2013). Furthermore, city planners/developers are faced with inadequate information on the dimensions of smart city required to achieve sustainable living (Badii et al. 2017).

Respectively, in achieving a smart city there is need for city planners/developers to make strategic decisions on how to implement smart city initiatives (Negre and RosenthalSabroux 2014). Hence, there is need to identify the smart city dimensions to be adopted by policy makers in deploying smart cities for sustainability attainment (David et al. 2012). Consequently, an approach is required to assist in retrieving and proving appropriate information as knowledge to guide decision-making process in smart city adoption (David et al. 2012). But, only few approaches such as big data (Anthony Jnr et al. 2020), internet of things (IoT), cloud computing have been employed to support smart city attainment (Anthony et al. 2016). Accordingly, this study aims to address the following research questions:

- What are the dimensions to be adopted by city planners/ developers in achieving a smart city?

- Which prior studies developed recommender systems in smart city domain?

- How can case-based reasoning (CBR) provide recommendations on smart city dimensions to be adopted in achieving a sustainable society?

To provide answers to the research questions, this study integrates CBR as an artificial intelligence (AI) technique similar to prior smart city study (Vázquez Salceda et al. 2014), to promote smart city planning. The CBR approach is utilized for addressing new problems based on the reuse of solutions to previous problems (Hu et al. 2012). Solutions from earlier problems are stored as cases in the knowledge base where each case has a solution and description parts stored in the knowledge base (Hotea and Groza 2013). The case description specifies the problem, whereas the case solution describes the source of the problem (Lorenzi and Ricci 2003). Hence, it is important to integrate CBR as an approach to provide prior examples (cases) to be used to evaluate, interpret, or solve a new problem in smart city planning to provide recommendation (Laurini 2013). As suggested by Lorenzi and Ricci (2003), CBR is integrated in this paper to provide recommendations on smart city dimensions to be adopted by city planners in achieving a smart city. The structure of the paper is organized as follows: Sect. 2 is the theoretical background, the application of CBR is presented in Sect. 3. Research methodology is presented in Sect. 4. Results are presented in Sect. 5. Discussions and implications are presented in Sect. 6. Lastly, conclusion is presented in Sect. 7.

\section{Theoretical background}

This section presents a literature review on smart cities approaches, smart city dimensions, knowledge continuum for smart city, background of recommendation system, prior recommender systems in smart city domain, and overview of case based reasoning.

\subsection{Literature review}

The concept of smart city was first addressed in 1994 (Jnr et al. 2018), but since 2011 several studies have been published to promote research and practice in smart city domain. A few of these studies that developed an approach similar to this study are reviewed as seen in Table 1 .

Based on the reviewed studies several approaches were employed to improve and make cities smarter. However, there are fewer studies that aim to provide recommendations as guidelines to stakeholders, city planners/developers on the dimensions of smart city to be adopted in achieving a sustainable society.

\subsection{Smart city dimensions}

A dimension is a feature or characteristic that varies within a study aimed at providing a complete and clear description of the area being investigated. Also, dimensions are employed in research to understand differences measured based on initiatives or attributes which are specific value of a dimension (Jnr et al. 2020a). Thus, this sub-section aims to provide answer to the first research question; what are the dimensions to be adopted by city planners/developers in achieving a smart city? Accordingly, the identified smart city dimensions (smart economy, smart mobility, smart environment, smart people, smart living, and smart governance) and associated initiatives are derived from the literature (Giffinger et al. 2007; Giffinger and Gudrun 2010; Mohanty et al. 2016; Bokolo and Petersen 2019) as seen in Fig. 1.

Figure 1 shows the identified smart city dimensions and related initiatives as suggested by Washburn et al. (2009). Each of these dimensions is discussed below.

\subsubsection{Smart economy}

Smart economy is a dimension that is determined by the flexibility of the labour force, innovation, entrepreneurialism, economic image, and the ability for a city to be transformed into a green city (Giffinger et al. 2007). It also 


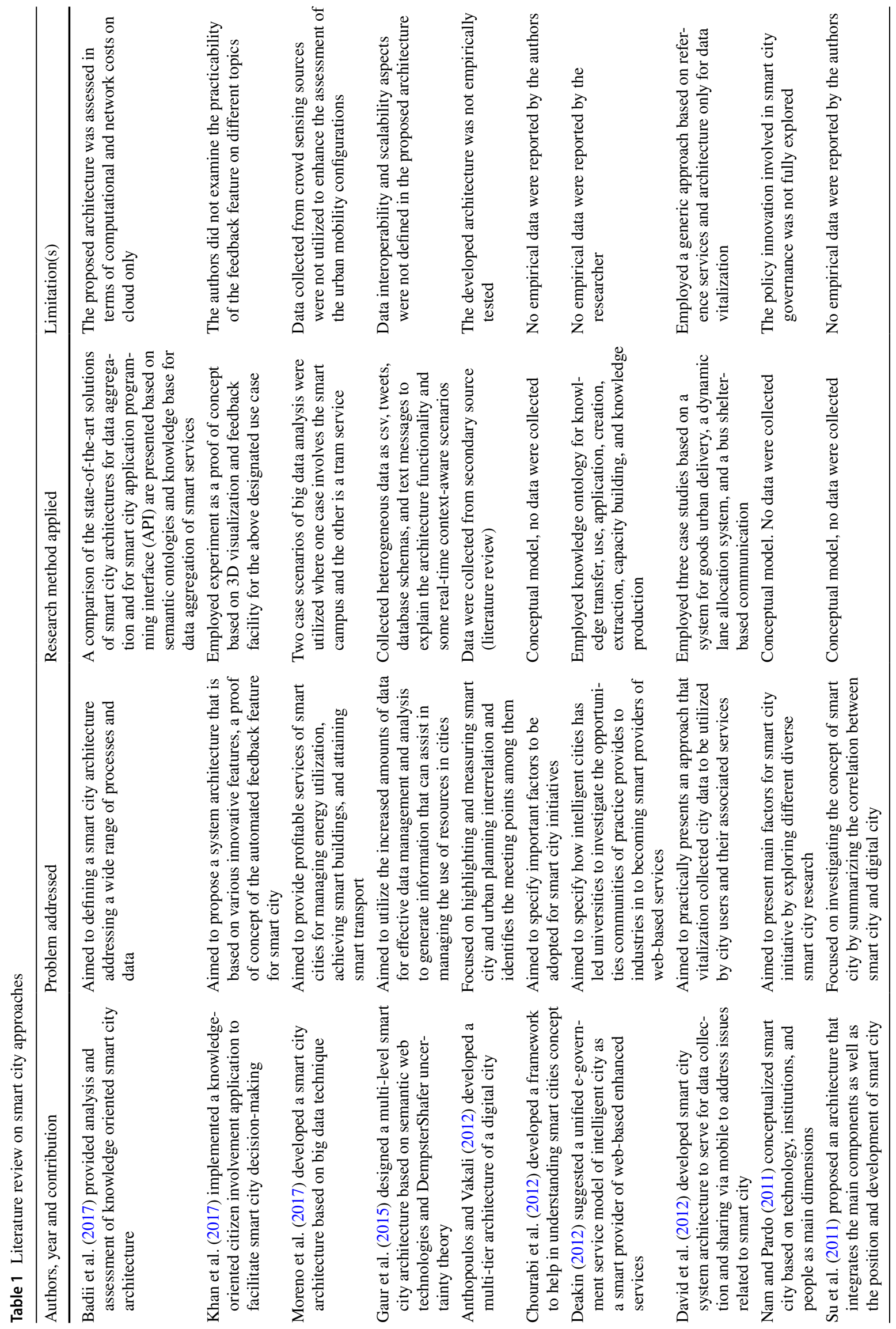




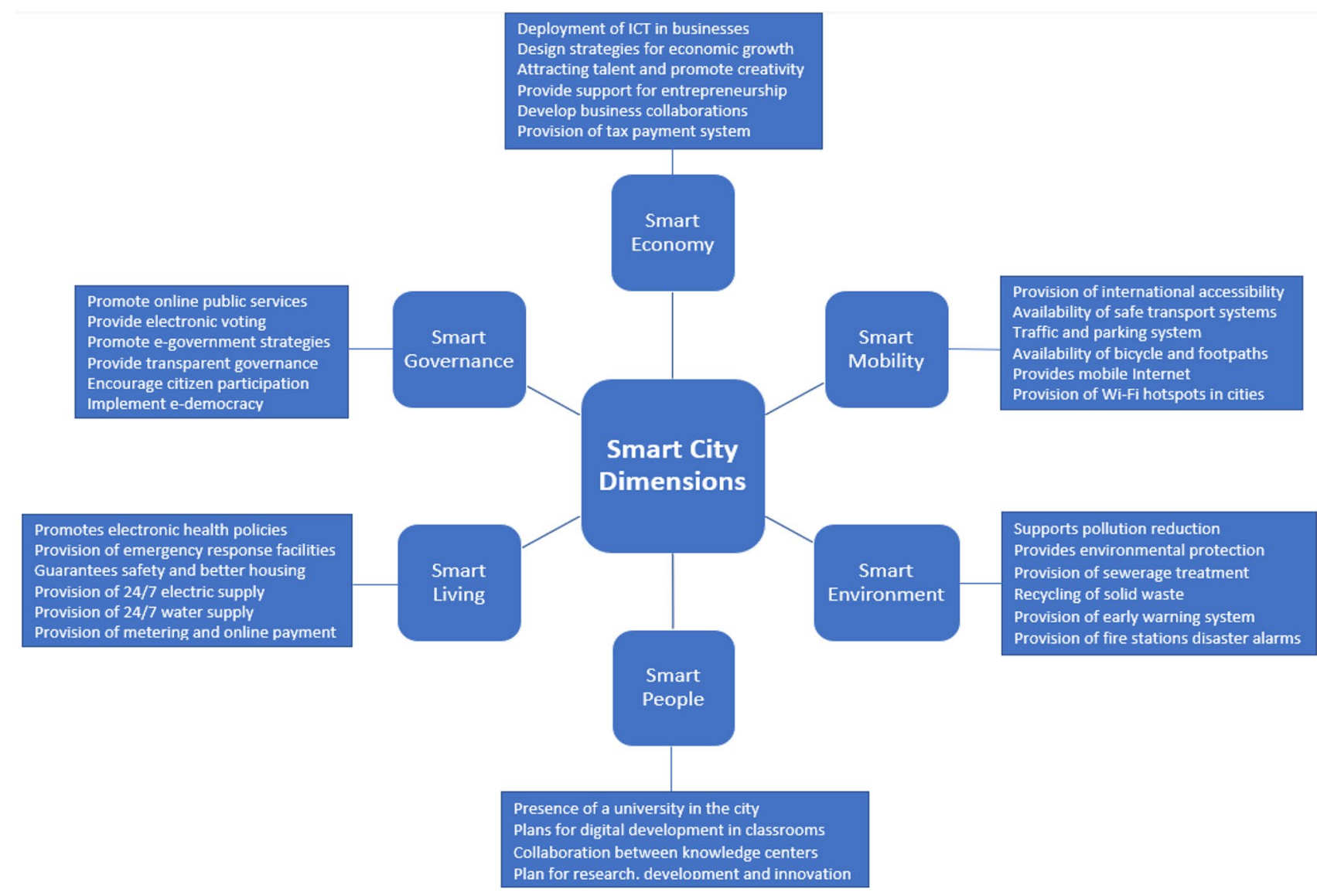

Fig. 1 Smart city dimensions

includes high economic competitiveness which improves the economic development of the city (Mohanty et al. 2016). A smart economy is mostly driven by the integration with global markets and possesses the ability to improve the economic competitiveness of the city (Bokolo and Petersen 2019). Additionally, the city's ability to attract visitors, business, capital, and talent also increases its economic growth (Giffinger and Gudrun 2010). But, findings from the literature (Tahir and Malek 2016) suggested that economic development has frequently been linked with the depletion of resources, resulting in adverse consequences for future development. Hence, it is significant that smart cities manage natural resources (Washburn et al. 2009).

\subsubsection{Smart mobility}

Smart mobility entails the accessibility as well as the availability of safe commuting systems, modern facilities, and green infrastructures (Mohanty et al. 2016; Jnr et al. 2018). It refers to local accessibility, availability of safe, modern, and sustainable transport systems. Besides, smart mobility involves providing citizens with access to innovative technologies, to facilitate urban routine in cities (Giffinger et al.
2007). Also, the available mobility infrastructures should support access to city mobility information for transport services. Hence, smart mobility entails the deployment of ICT as a way to revitalize transportation operations in order to achieve affordable mobility. Thus, cities should implement ICT to enhance mobility as an approach to building a digital and integrated transportation network (Jr et al. 2017).

\subsubsection{Smart environment}

In smart cities, the environment dimension relates to the preservation of natural resources such as water, clean air, land, etc. (Tahir and Malek 2016). It involves the green utilization of natural resources, protection of natural habitat, reduced pollution, and sustainable management of resources (Giffinger et al. 2007). Smart environment is also determined by the attractiveness of natural conditions and the responsible resource management for the ever-decreasing resources and ever-increasing demands (Mohanty et al. 2016). Accordingly, smart environment denotes the use of technologies to protect and preserve the city's natural environment and is characterized by security and trust, use of ICT to improve 
cultural initiatives, municipal safety for the digitization of tradition assets (Bokolo and Petersen 2019).

\subsubsection{Smart people}

Smart people include social communities and humans that reside in the city. The participation and involvement of the people is a criterion that influences smart city attainment (Mohanty et al. 2016). Thus, for a city to be smart, the citizens need also to be smart to achieve an inclusive, innovative, and sustainable city (Jr et al. 2017). The smart people dimension includes social and human capital, tolerance, creativity, and participation in public events. In smart city, the residents are smart in terms of their skill and educational levels, as well as the value of social collaboration in terms of integration of public life and their ability to communicate with one another (Giffinger and Gudrun 2010). According to Tahir and Malek (2016), other factors may include social and ethnic plurality, level of qualification, affinity to lifelong, and open-mindedness.

\subsubsection{Smart living}

Smart living involves improving citizens quality of life by changing their home, communities, workplace, energy and transportation infrastructures into green environments (Giffinger et al. 2007). Smart living improves the understanding of how technology and society interact for the benefit of citizens (Mohanty et al. 2016). Hence, smart living is about adapting factors that make up a meaningful and happy life (Jr et al. 2017). It entails several factors (e.g. health, education, tourism, safety, culture, etc.) (Tahir and Malek 2016), that improve the quality of life of inhabitants leading to a more harmonious, and satisfactory life (Bokolo and Petersen 2019).

\subsubsection{Smart governance}

Smart governance involves deploying ICT to support decision-making and planning for policy makers (Giffinger and Gudrun 2010). It entails improving self-governing procedures and changing how community services are dispersed (Jr et al. 2017). Moreover, it is concerned about public leadership and services for greater efficiency and continuous development through ICT innovation such as e-democracy or e-government (Giffinger et al. 2007; Bokolo and Petersen 2019). It involves enhancing democratic procedures and transforming how public services are carried out by city leaders (Mohanty et al. 2016). Smart governance aims to achieve transparency of governance systems and better quality of political strategies for better public service delivery (Tahir and Malek 2016).

\subsection{A review of knowledge continuum for smart city}

Smart city comprises of data, information, knowledge, and wisdom, which is known as the knowledge continuum as shown in Fig. 2. Respectively, data refer to a collection of numbers, text, or symbols in unorganized or raw format that needs to be processed to derive meaning (Watson 2001). Data are comprised of unfiltered, unrefined basic format. Information involves processed data that have been structured typically by a computer, to provide meaning that is interpretable (Anthony 2020). When data are processed as information, it becomes significant, gains meaning and have changed to the format of being beneficial (Deakin 2012). Conversely, knowledge refers to individual acquisition of

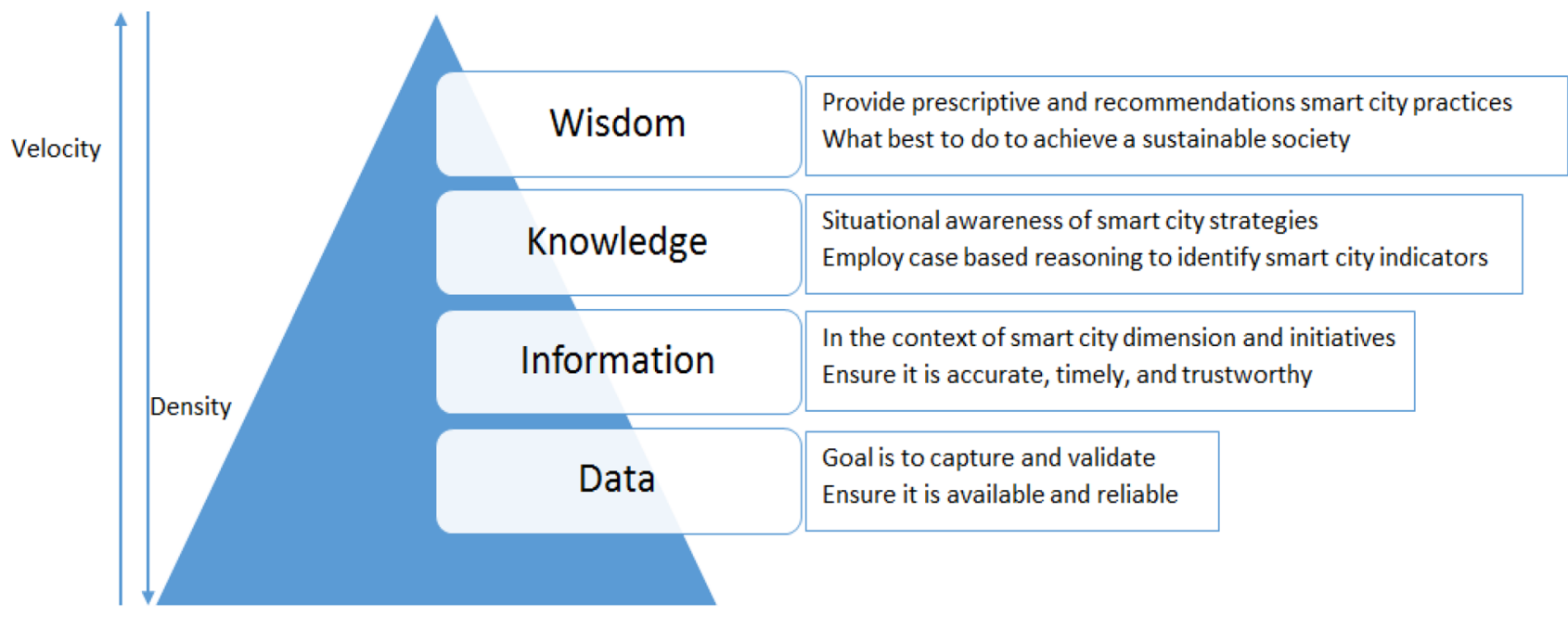

Fig. 2 Knowledge management for smart city attainment 
information, for example the understanding of information or facts on how to resolve certain issues (Anthony 2020). Knowledge exists in the individual and happens only when user insight and experience are practical to data and information. Wisdom is knows-what or recognition, ability to act or knows-how, and understanding or knows-why that exist in or within the mind of an individual (Laurini 2013).

Figure 2 shows the transformation of data through knowledge management for smart city attainment. Furthermore, smart cities are based on knowledge intensive and creative schemes aiming at improving the environmental, socioeconomic, social performance of cities (Laurini 2013; Anthony et al. 2019). Accordingly, to plan and manage a city, an innovative approach through knowledge engineering which entails the design and deployment of a knowledgebased infrastructure is needed (Hoadjli and Rezeg 2019). Thus, Fig. 2 depicts that data which represent raw measures, information concerns data with meaning and knowledge are information which can be useful to solve a problem. Moreover, by applying knowledge, a sort of decision-making (wisdom) can be achieved to promote smart city development.

Figure 3 depicts the role of knowledge in promoting smart city polices. Moreover, Fig. 3 illustrates the role of knowledge infrastructure in a smart city which is based on a physical layer which involves sensors, communications, and data on smart city dimensions and associated initiatives (Laurini 2013). Hence, open data from sensor and other connections relating to smart cities initiatives are used as information to provide knowledge to city developers/planners in making decisions on how to make cities smarter.

\subsection{Background of recommender system}

Recommender systems emerged from the domain of knowledge discovery and have been utilized to identify patterns in huge datasets. Recommender systems employ data filtering in presenting information to users (Hoadjli and Rezeg 2019).
Recommender systems characterize a type of software systems that produce meaningful recommendations of interest for users and aid the users in decision support (Khan et al. 2020). Recommender systems utilize data mining techniques in providing suggestions based on aggregated data. It entails a description of user keywords that is either matched in the data catalog (Abu-Issa et al. 2017). A typical recommender system collects input and aggregates the collected data to provide recommendations to recipients (Casino et al. 2017). Recommender systems have been deployed in many fields such as data warehouse, information retrieval, e-commerce, cognitive science, web usage mining, and many others (Negre and Rosenthal-Sabroux 2014).

In smart cities, a plethora of data are generated which provides enormous amount of information, thus there is need for an approach which possesses the capability to filter data that support search for information. Accordingly, a recommender system can be deployed as an approach (Lorenzi and Ricci 2003; Alyari and Jafari Navimipour 2018), that support users to get contextual information needed to make decisions (Zhitomirsky-Geffet and Zadok 2018; Zare et al. 2019). There are four types of recommender systems applicable to smart city domain. They include collaborative filtering recommenders, content-based recommenders, hybrid recommenders, and knowledge-based recommenders as seen in Fig. 4.

Figure 4 depicts the types of recommender systems, each of the systems are described below:

\subsubsection{Collaborative filtering recommenders}

Collaborative filtering is the most popular approach, whereby recommendation is carried out through real-life collaboration such as user A recommends information to user B (Benfares et al. 2016). This is interpreted in the systems as the situation that users are more likely to be interested in information that are already liked by other users
Fig. 3 Knowledge infrastructure roles in a smart city adopted from Laurini (2013)

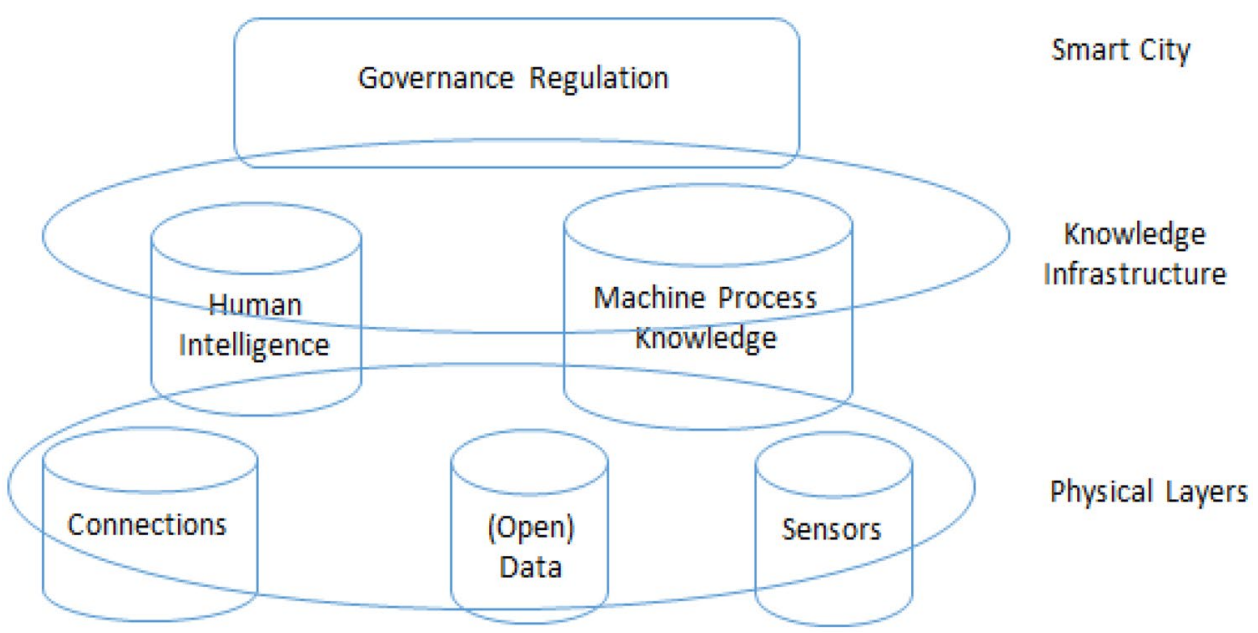




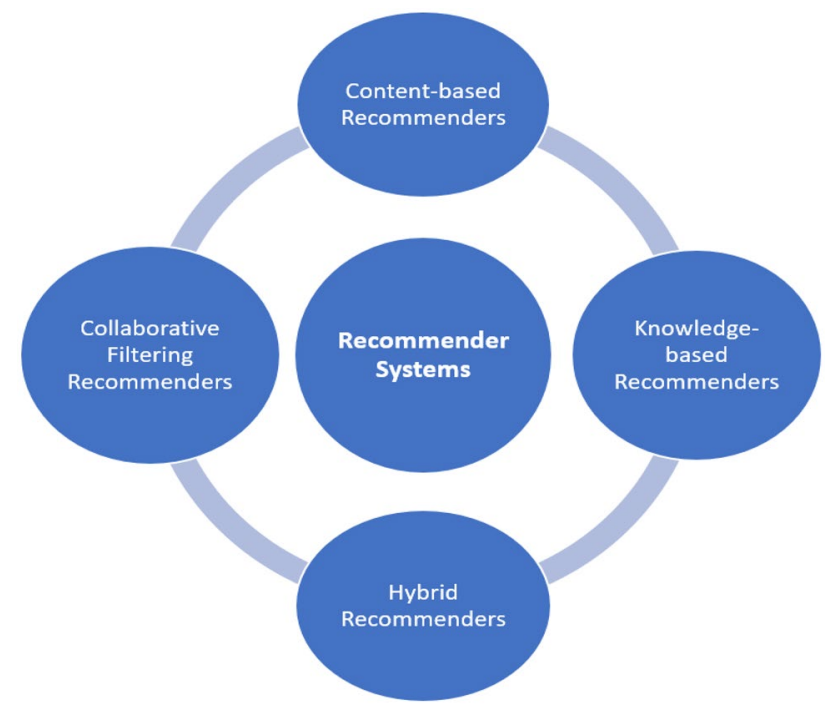

Fig. 4 Types of recommender systems

with similar interest (Faieq et al. 2019). Collaborative recommender aids sharing of knowledge and/or experiences among users who have similar interest (Alrawhani et al. 2016; Alyari and Jafari Navimipour 2018). The limitation of this method is that new information is not recommended till it has enough user ratings (Abu-Issa et al. 2017).

\subsubsection{Content-based recommenders}

The content-based recommenders deploy a different approach, where recommendation of items is aligned to ratings of prior users. This similarity is measured based on the item's characteristics (Alrawhani et al. 2016). Thus, contentbased recommender is based on the notion that information of an item can easily be defined into categorical data types. This approach entails a strong domain knowledge, which can be challenging to maintain (Faieq et al. 2019). In the content-based recommender, some types of information such as multimedia are not easy to analyze (Alyari and Jafari Navimipour 2018). The main limitation of this system is that it does not recommend information to the user except if he/she likes similar information in the past (Abu-Issa et al. 2017).

\subsubsection{Hybrid recommenders}

The hybrid recommenders include the combination of collaborative filtering and content-based recommender systems (Alrawhani et al. 2016; Abu-Issa et al. 2017). Hybrid recommenders aim to strengthen the recommender to address the limitations of each individual method (Faieq et al. 2019). Hybrid recommender systems enhance prediction performance and also improve complexity and outlay for implementation. Although, it requires external information to be functional which is mostly not available (Alyari and Jafari Navimipour 2018).

\subsubsection{Knowledge-based recommenders}

Knowledge-based recommenders do not provide recommendations grounded on user requirements, but on user's knowledge about the characteristics of the needed information. These systems characteristically compute suggestion based on keywords provided by the user (Alyari and Jafari Navimipour 2018). This approach offers recommendations using explicit qualitative knowledge of the user. Although, this approach entails deep suggestion ability and is mostly static. It recommends information according users' preferences (Khan et al. 2020).

\subsection{Prior recommender systems in smart city domain}

This sub-section aims to provide an answer to the second research question; which prior studies developed recommender systems in smart city domain? This sub-section reviews related research that developed recommender systems in smart city domain. Among these studies, Khan et al. (2020) implemented a recommender system to facilitate smart markets based on mobile cloud and context-aware method that provide available services to citizens. The proposed recommender system comprises of cloud back-end layer, data analytics, context sensing, and recommended entities (potential customers and digital marketplaces). Also, Faieq et al. (2019) proposed a context-aware recommendation system to provide service composition in smart environments. The researchers aimed to resolve huge number of available services and improve strong collaboration between stakeholders and providing relevant services to the users. Hoadjli and Rezeg (2019) designed a recommender system for smart city. The authors aimed at enhancing city's digital services for citizen's context supported by cloud approach deployed to enhance system scalability. An experiment was deployed to test the scalability and interactivity by measuring the data exchanged and response time.

Another study was conducted by Habibzadeh et al. (2018) where data analytics, machine intelligence, and soft sensing were integrated to design a recommender system in smart cities. The application of the techniques facilitates data processing by retrieving only relevant information to support soft sensing within smart city applications. Similarly, Di Martino and Rossi (2016) proposed an architecture for a mobility recommender tool in smart cities. The recommender tool deployed a vehicle-based multimodality that supports user in planning their trip and also provides suggestions for parking facilities for all public transportation. 
The architecture comprises of mobility user application, ranked list of routes, recommender system, and data sources (dynamic and static). Yavari et al. (2016) developed a customized parking recommender system to provide service delivery in smart cities. IoT was utilized for data discovery from sensors in offering personalized information to users. The authors applied their approach for smart parking space and also conducted an experimental validation to show the benefits of their solution.

Abu-Issa et al. (2017) implemented a proactive, multitype, and context-aware recommender application in smart city. The recommendation system suggests multi-types of services and proactively pushes explicit query suggestions to users. Furthermore, Benfares et al. (2017) applied semantic of services to provide recommendations in smart cities to address the generation and selection of customized and relevant services to support real-time decision making of users. Additionally, Benfares et al. (2016) designed a personalized architecture for patrimony tourism recommendation services in smart city. The architecture utilizes collaborative filtering method to provide personalized tourist recommendation services based on user's profile. Casino et al. (2017) designed a context-aware mobile recommender to improve healthy routes in smart city. The suggested method provides adapted recommendations of user's exercise routes based on their medical state and real-time data from the smart city.

Cortés-Cediel et al. (2017) deployed a recommender system to promote e-governance in smart cities. The authors aimed to address the lack of personalization in services for specific users and stakeholders, which is identified as one of the issues faced in smart cities. Casino et al. (2015) suggested a context-aware recommender system for smart health. The researchers aim to provide healthcare services for citizens in smart city to promote their quality of life. The scheme comprises of sensing infrastructure to provide citizens with suggestions on their preferences and health conditions. Negre and Rosenthal-Sabroux (2014) designed a recommendation approach based on the smart city dimensions to improve the smartness of a city. Their approach also helps to predict users' ratings regarding smart cities items. Lastly, Luberg et al. (2011) developed a rule-based tourist system in smart city to provide custom-made recommendations using probabilistic reasoning.

Implications from the reviewed 14 studies, suggest that none of the research explored how AI can be employed to develop a recommender system to support smart cities. Although, the reviewed studies developed recommender systems to addressing different issues in smart cities, there are few studies that employed a typical knowledge approach to provide recommendations on the smart city dimensions to be adopted by city planners/developers in making cities smarter. Thus, in this study the knowledge-based recommenders' approach (see Sect. 2.4.4) is employed and CBR is deployed as an AI technique to provide recommendations on the smart city dimensions and associated initiatives to be adopted by city planners/developers. Thus, this study integrates knowledge-based approach via CBR to develop a recommender system towards promoting smart city planning.

\subsection{Overview of case-based reasoning}

Case-based reasoning originated from the research of Schank and Abelson (1977) and has developed into an advanced and significant field of AI. CBR has been previously employed in domains such as in business, management, education, engineering, medical, architectural, etc. (Watson and Gardingen 1999; Yeh and Shi 1999; Lorenzi and Ricci 2003; Madkour et al. 2015; Lee and Kim 2015; Alrawhani et al. 2016). When challenged with a new and complex problem, it is natural for a problem-solver to search his or her memory for prior similar experiences for help. CBR utilizes tacit knowledge from expert who can remember and properly use the relevant previous cases (Watson 2001). Thus, CBR is a knowledge-based system (KBS) solution and its philosophical goal is to use similar prior case(s) (problem and solution) to help solve, assess, or deduce a new problem (Yeh and Shi 1999).

Furthermore, the process of deploying a CBR to help address a new problem is very analogous to that which happens in the human brain. CBR perceives knowledge as encapsulated experience and its knowledge base comprises of a case library in which the encapsulated memories are stored as actual stories (Lee and Kim 2015). Thus, after the user inputs the descriptions of a new problem, CBR searches for similar cases in the case library according to the predefined matching algorithms (Madkour et al. 2015). Moreover, the cases which meet the searched keyword criteria are retrieved and their solutions or any other parts of the stories required by the user are directly used or adapted to before being utilized (Anthony Jnr et al. 2019). The user can evaluate whether the retrieved solutions work well or not and modify them before use. Therefore, when a usable solution is obtained, the newly solved problem can be retained in the case library as a new case and the knowledge of the CBR system improves (Yeh and Shi 1999; Anthony et al. 2016). The CBR cycle comprises of four main phases as seen in Fig. 5.

Figure 5 depicts a typical CBR structure which comprises of retrieving of most similar case(s), reuse of case(s) to solve current problem, revise the retrieved and selected solution if necessary, and retain the new adopted solution as a part of a new case. In the CBR cycle, the cycle begins when a new problem is matched against exiting cases in the library and one or more analogous cases are recovered. Except the case where the recovered case is a close match to the new problem, the solution will most possibly have to be revised to create a new 


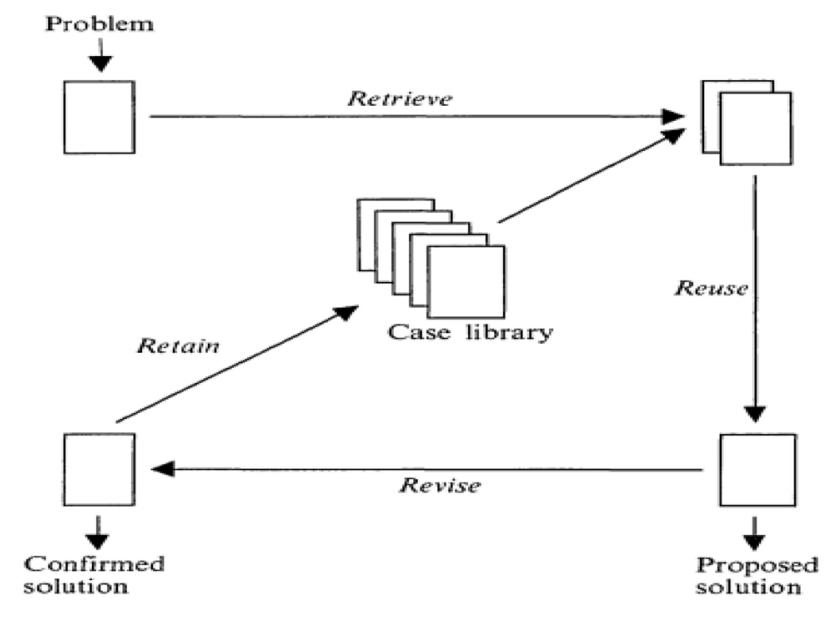

Fig. 5 Typical CBR structure

case that can be saved (Lee and Kim 2015). In comparison of CBR and ordinary database systems, CBR have the capability to adapt retrieved cases although adaptation is one of the most challenging procedures of CBR as such many CBR-based systems disregard this phase (Yeh and Shi 1999).

Second, the retrieval procedure of CBR is more active such as CBR is much more robust in evaluating and dealing with incomplete problem explanations that differ from the characteristics employed to store each case in the case base (Alrawhani et al. 2016). Furthermore, the traditional database retrieval approach is designed to match exactly queries based on information stored in the knowledge base, whereas CBR retrieves the most similar cases which also include cases with different attributes or parameters based on the specified search query. Hence, CBR retrieves cases not only base on the parameter content of the case but also assesses if the cases are a better fit (Madkour et al. 2015). Accordingly, CBR is adopted in this study analogous to Yeh and Shi (1999) who applied CBR to develop a planningsupport system tool for urban planning and Orłowski et al. (2016) where the authors adopted CBR for the deployment for smart cities system design.

Due to the fact that smart city is still evolving but has been proposed in prior publications, there are fewer studies that attempt to explore smart city dimension to be deployed to improve the smartness of city. A recommender system facilitated with an AI technique such as CBR technique is a promising field of inquiry. To the best of our knowledge, this is the first study that employed CBR to implement a knowledge-based recommender system to make cities smarter based on identified smart city dimensions.

\section{Application of case-based reasoning}

This section aims to address the third research question; how can CBR provide recommendations on smart city dimensions to be adopted in achieving a sustainable society? Correspondingly, this section presents the applicability of CBR technique and its application in providing recommendation to city planners/developers in adopting smart city dimensions and associated initiatives. CBR as proposed by Schank (1977) draws on cognitive theories of human memory, problem solving, and learning and is technically described as an approach which comprises of the following steps which include case representation and indexing, case retrieval and adapting, case reuse, case revision, and case retention as presented in Fig. 6 which depicts the developed CBR smart city architecture. Also, the code to each of the CBR phases is presented in Git hub in https://github.com/bktonny/Smart -City-Recommender-Tool.git.

Figure 6 shows the developed CBR smart city architecture, which start with the smart city experts adding new smart city initiatives into the knowledge base as knowledge acquisition. Then, the city planners/developers search for smart city practices based on keywords. Additionally, Fig. 6 comprises of case selection which employs case retrieval and matching of similar case, followed by case classification which involves case reuse adaptation. Then, its case customization which involves case revision, followed by case retaining and learning and lastly the case is saved in the knowledge base which contains all the smart city dimension and initiatives. The requested information is displayed to the city planners/developers as knowledge representation on how they can successfully adopt smart city practices in achieving a sustainable society. Each of the CBR procedures is described below.

\section{Smart city initiative case representation and indexing}

Case representation is an important procedure in CBR as it supports for better measurement of similarities of current problems as compared to prior cases. The case representation contains information that describes a case that has a direct effect on the outcome or the solution of that practice. The case base (knowledge base) stores all information about problems (conditions) and solutions (actions) for past smart city situations. Thus, a case is utilized to represent knowledge of diverse cases and contains new learning experiences. Accordingly, city planners/developers search for cases and CBR executes similarity matching when searching for information from the knowledge base using query language for retrieval. Therefore, Table 2 depicts an example of case a 
Knowledge Representation

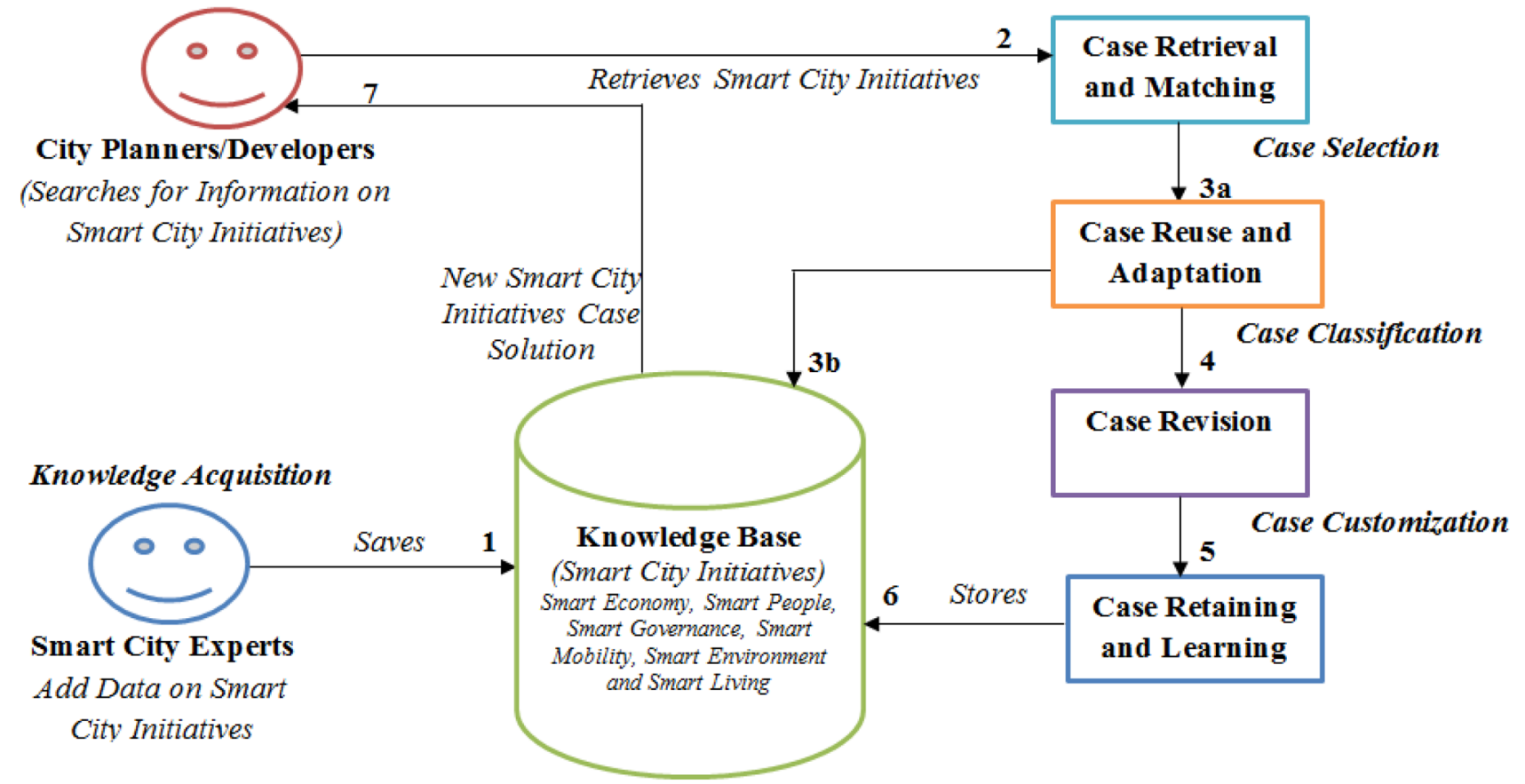

Fig. 6 Developed CBR smart city architecture

typical smart city initiative case in the knowledge base. Likewise, Table 8 in appendix shows a summary of equations, variables/symbols, and definitions used for Eqs. (1-15).

Table 2 depicts how a smart city initiative case is indexed in the knowledge base, where the process of case indexing entails assigning labels to each smart city case when entered or stored by the smart city expert into the knowledge base to ensure easy retrieval of cases.

Figure 7 shows an example of a smart city initiative case structure, which signifies successful experienced smart city case initiative description to be employed by city planners/developers for decision according to their own context. Figure 7 also depicts the smart city case initiative index, type, condition description, and action which

Table 2 Smart city initiative case representation

\begin{tabular}{ll}
\hline Case attributes & Parameters value \\
\hline Smart city case index & Numeric \\
Smart city case number & Integer \\
Smart city case name & Text \\
Smart city case dimension & Text \\
Smart city case source & File \\
Smart city case start date/time & Date \\
Smart city case end date/time & Date \\
Condition description & Text \\
Action (prediction solution) & Text
\end{tabular}

describes successful process involved in the case. Figure 7 shows the retrieval and mapping of cases on smart city initiatives which are based on the smart city dimensions derived from Fig. 1.

\subsection{Case retrieval}

Case retrieval aims to find the most similar case from the knowledge base in relation to the keywords of the searched case. CBR depends on this phase to address new problem searched by the city planner/developer. The retrieval of similar cases in CBR recommender system is based on the comparison of the weight of the new problem to the existing solution in the knowledge base. This can be deployed using the nearest neighbor (NN) algorithm. Thus, for NN algorithm, the similarity of two cases existing smart city initiative solution and new smart city initiative are computed in Eq. (1).

$\operatorname{SCS}(c)[x i] . n=\operatorname{SCS}(c)[x i] . n+1$,

where case $c$ and $c^{\prime}$ signify the nearest neighbors of solution $s$ and $s^{\prime}$, which are related to the same case, and the smart city initiative $i$ in the knowledgebase can be calculated by Eq. (2).

$i=1 / 1+\operatorname{SCS}(c)[x i] . n$. 


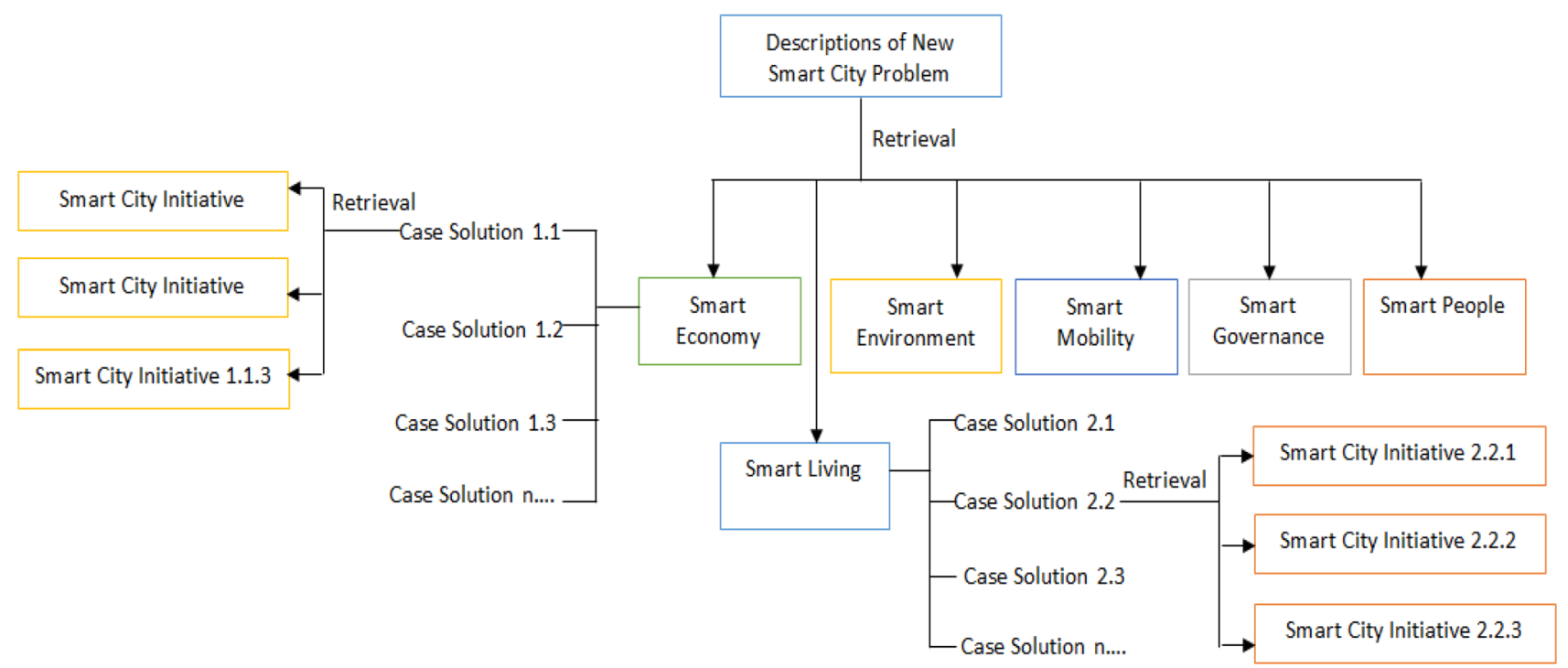

Fig. 7 Retrieval of cases for smart city initiatives

Fig. 8 Flow diagram of the proposed CBR smart city recommender system

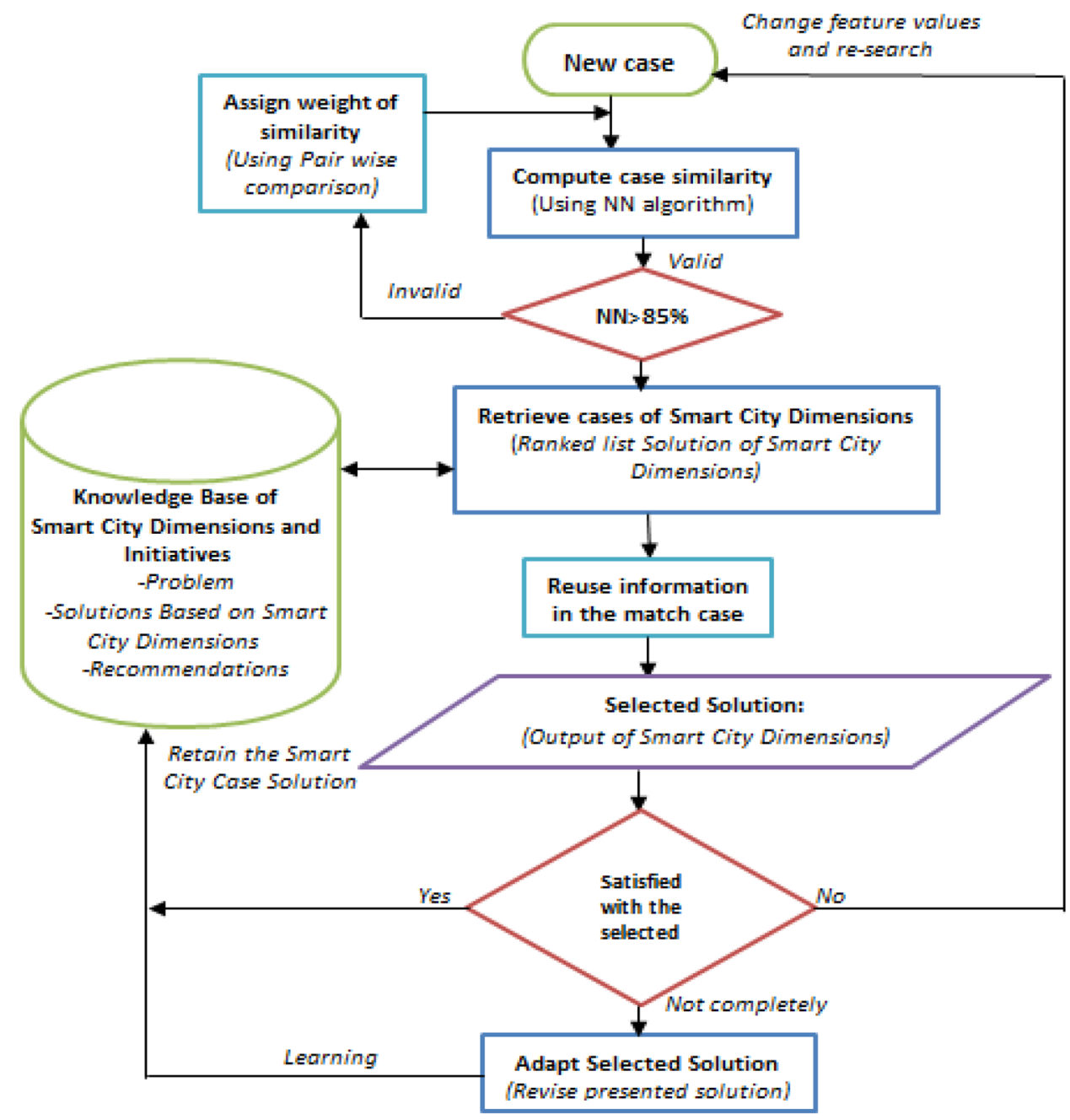


Additionally, Fig. 8 depicts the flow diagram for the CBR smart city architecture which presents a flow diagram to summarize how the proposed CBR smart city recommender system retrieves smart city initiatives cases and use these cases to solve a new problem by providing information as recommendation guidelines to city planners/developers in developing a smart city towards attaining sustainability. The flow starts with an initial description of a problem, which expresses a new case without solutions.

This new case comprises of a number of smart city dimensions input features added by the case requester (city planner/developer) as shown in Fig. 8, which is used to retrieve similar cases from the knowledge base. The retrieved cases are chosen from data that are stored in the knowledge base. After retrieving these cases, the city planner/developer will reuse the identified solutions to recommend a new case solutions. The proposed solutions contain information about the implementation of smart city initiatives (see Fig. 1). In addition, Fig. 8 shows how city planner/developer can search for similar smart city cases from knowledge base to check if the retrieved solutions are suitable, if the solutions are not usable the solution can be modified by the user by reselecting other feature values and re-running the process again to improve the solutions or by adapting the new case. When the user is satisfied with the solutions, the case will be retained, and the knowledge base is updated by storing it as a new learned case. This phase will develop the library of cases and can be retrieved in future by re-using the new solutions for the next new case. This can be seen in Sect. 3.4.

Furthermore, weights are assigned to enable the CBR recommender system to calculate the similarity between the problem and cases as stated previously. These weights are not static, thus smart city expert or city planner/developer can also assign their importance based on the categorization of the problem, thus enabling the searching process to be more efficient and flexible to the requests of the user. However, the weighting is carried out using NN algorithm and SQL which uses pairwise comparison to compare and be certain of the most suitable case similar to the problem queried by the city planner/developer the process involves the integration of a square matrix $A 1 n^{*} n$ in which the set of features are pair wise compared. Where, $A 1 n^{*} n$ can be denoted as seen in Eq. (3),

$A 1 n * n=a 11, a 12, \ldots a 1 n$.

Thus, if aij is the smart city initiative in the pair wise comparison matrix, it gives a comparative significance of a criterion $I$ with respect to criterion $j$ as seen in Table 3 . In matrix $A 1 n^{*} n$, aij=1 when $i=j$ and $a i j=1 / a i j$ where $i \neq j$, employed to retrieve similar cases from the knowledge base based on the assigned weights. Furthermore, the weights related with each smart city initiative are computed by
Table 3 Numerical rating for pair-wise comparison

\begin{tabular}{ll}
\hline Intensity of significance & Definition \\
\hline 1 & Equal importance \\
3 & Moderate importance \\
5 & Strong importance \\
7 & Very strong importance \\
9 & Absolute importance \\
$2,4,6,8$ & Intermediate values between \\
& the two adjacent judge- \\
& ments \\
\hline
\end{tabular}

geometric mean GMi. The geometric mean can be stated as seen in Eq. (4).

$\mathrm{GM} i=[\pi n j=1 * a i j] 1 / n$.

Therefore, if $n=1,2,3, \ldots, i$. Table 3 shows the values assigned to each smart city dimension in retrieving cases from the knowledge base. These values of $n$ searched by the user are used in the NN algorithm shown in Eq. (1-3) in searching for cases similar to the problem specified by city planner/developer.

Then, the geometric mean is normalized to obtain the relative smart city initiative case weight with a value of $W i$, for each smart city dimension. Hence, the normalized resulting case weight can be stated as shown in Eq. (5).

$W i=\mathrm{GM} i / \sum n i=1 \mathrm{GM} i$.

\subsection{Case matching}

Matching aims to measure the extent of similarity between smart city case initiatives by comparing their features as presented in Table 2 to retrieve the most suitable cases for a specified context. In the matching procedure, the similarity measure is executed by CBR when comparing all smart city dimension cases features and context data both stored in the knowledge base. For similarity, the string match (SM) is employed for smart city initiative case string computation. Assuming $D$ is the list of all smart city dimensions and CC is smart city case initiatives of all case in the knowledge base. So, for each smart city case SC in the knowledge base, SM for each smart city initiatives in the knowledge base is computed by Eq. (6),

$\mathrm{SM}(\mathrm{SC})=\{x \in D / \exists y \in \mathrm{CC}, E(x, y)=0\}$,

where $E(x, y)$ is the Levenshtein distance which measures the similarity based on the distance concept. Also, from 
Eq. (6) SM (SC) retains the smart city dimensions of $D$ that are possibly similar as compared to the current case CI. Thus SM (SC) denotes the number of similarities in common between the new case and existing case in the knowledge base. For CBR to choose a similar case, a threshold $t$, is used in the measurement of the case similarity among cases. So, for each case Eqs. (7) and (8) are given as

$\{$ smart city $(D)$ - smart city $(\mathrm{SM}(\mathrm{SC})) \leq t\}$,

$\{$ smart city $(D)-\operatorname{smart} \operatorname{city}(\mathrm{SM}(\mathrm{SC}))>t\}$.

Next, for Eq. (7), the case is retained and for Eq. (8) the case is declined based on the computed SM (SC) values of existing case in the knowledge base. Likewise, as each smart city dimension is different, the context attributes are also different. Thus, each smart city initiative case that is relevant is assigned a weight based on threshold ' $t$ ', specified by smart city expert when he/she entered the case in the knowledge base. Thus, if the summation of all the smart city initiative attributes' weights is higher than ' $t$ ' value which is usually set at 0.5 as recommended by Madkour et al. (2015), the case is considered appropriate to the city planner/developer in making decision over the smart city dimension context.

\subsection{Case reuse and adaptation}

This phase involves the utilization of retrieved cases from the knowledge base that provides possible solutions to city planner/developer aimed at addressing the current smart city problem. CBR approach executes a query containing information about a defined problem, based on the problem context and returns a list of $n$ most similar cases or cases with similarity not less than the specified threshold as stated previously as $85 \%$ (see Fig. 8) based on the NN algorithm. In most occasions, before the city planner/developer uses the retrieved case, the case may be adopted, where in the adaptation of case the city planner/developer updates the retrieved case to suit his/her present context.

Moreover, the adaptation has been argued as an important phase of CBR as it inputs intelligence to existing cases which is significant due to changes in technology as the year progress. Thus, adaptation means refining existing solutions to find a better match set from present cases. Also, in the CBR technique, the best match case may sometimes entail the combination of one or more cases. CBR uses the NN procedures to check for best match between the solutions in the knowledge base and the current cases. The adaptation allows the update of smart city initiatives; therefore, it entails a context $X$, for every retrieved case $C$, where the distance to the context is calculated by fuzzified weighted Euclidean distance using the Eq. (9) for appropriate smart city initiative case retrieval.
$(X, C)=\left(\sum i=n, n=1 w i((x i-c i)) 2\right) 1 / 2=0.290$,

where $c i$ and $x i$ are the 'attributes' (case properties) corresponding to the matched attributes of the current smart city problem and $(x i-c i)$ which is the fuzzified partial distance. In the context of this study, $(D, \mathrm{SC} 1)$ is smart city initiative 1 and $(D, \mathrm{SC} 2)$ is smart city initiative 2 which represent both smart city initiatives. Thus, the adoption of SC1 and SC2 initiatives is based on $D$ which is the smart city dimension that the smart city initiative is based on. Accordingly, the equation is represented as

$\left.(D, \mathrm{SC} 1)=\left(\sum i i=n=1 w i(x i-c i)\right) 2\right) 1 / 2=0.300$,

$(D, \mathrm{SC} 2)=\left(\sum i i=n=1 w i((x i-c i)) 2\right) 1 / 2=0.290$.

After applying Eq. (9), new Eqs. (10) and (11) are derived, where 0.300 and 0.290 are the weighted values assigned by the smart city expert. As shown from distances, values of 0.300 and 0.290 , there is no identical case to the context, so the calculation of a tradeoff among $\mathrm{NN}$ is fixed. Where SSC1 is the solution employed for smart city initiative case $\mathrm{SC} 1$, which is $35 \%$ correct, and SSC2 is the solution employed for smart city initiative case $\mathrm{SC} 2$ which is $65 \%$ accurate at the time of case usage. The average of these two smart city initiatives case values is given as

$(0.29 / 0.29+0.3 * 35 \%)+(0.3 / 0.29+0.3 * 65 \%)=50.29$.

The final result signifies that the new adopted smart city initiatives case is now $50.29 \%$ accurate and the new solution can be adopted based on the city planner/developer feedback after which the case can be utilized to address new problem.

\subsection{Case revision}

After an adapted solution to the new problem has been employed by updating the existing cases, the most recent adapted cases can serve as references if the knowledge base does not contain a solution to the new problem. Thus, for a solution case, there is need to directly reflect city planner/ developer feedback into the existence value of the smart city initiative case. Therefore, Eq. (12) defines how the existence value $\operatorname{ESC}(c)$ of a solution case $\mathrm{SCI}$ is restored:

$\mathrm{ESC}($ new $)(\mathrm{SCI})=\mathrm{ESC}($ old $)+\Delta \mathrm{ESC}(\mathrm{SCI})$.

Equation (12) suggest that $\mathrm{ESC}$ (new) is the combination of $\mathrm{ESC}$ (old) the previous version of the case in addition to the adapted version of the $\triangle \mathrm{ESC}(\mathrm{SCI})$. 


\subsection{Case retaining and learning}

In the CBR cycle, retaining the case involves saving new or the adapted/updated case into the knowledge base. This entails the process of selecting the information to save to be utilized for future smart city implementation retrieval. Thus, in this phase, each case is assigned a survival value SV which denotes how important and how many times the case has been used as saved in the knowledge base, serving as a medium to maintain the knowledge base. Moreover, the decrement or increment of the survival value of a smart city initiative case depends upon its degree of satisfaction from users (city planners/developers). Currently, the levels of satisfaction or degree of satisfaction 'Sat' can be measured based on the following:

Highly satisfied $=>0.80$,

Satisfied $=0.65$ where $<$ Sat $<0.80$,

Unsatisfied $=0.45<$ Sat $<0.65$,

Highly unsatisfied $=0.25<$ Sat $<0.45$ and Sat $<0.10$.

At first, when a new case is added in the knowledge base, it's assigned an initial survival degree value that is equal to the threshold to survive as seen in Eq. (13):

$\mathrm{SC}($ new $)=\mathrm{SC}($ old $)+\Delta \mathrm{SV}(\mathrm{SC})$.

After, which the case may be adapted to a new case based on the inputs or feedbacks from the city planners/developers. Then, its survival value is updated by Eq. (14):

$\Delta \mathrm{SV}(\mathrm{SCC})=(\operatorname{Sat}(\mathrm{SCC})-0.45) \times \alpha, \operatorname{Sat}(\mathrm{SCC})$.

From Eqs. (14) and (15), suggest that SV(new)(SCC) is the combination of SR(old)(SCC) which is the previous retained version of the case in addition to the adapted retained version of the $\Delta \mathrm{SR}$ (SCC). Where, from Eq. (15) the satisfaction degree (feedback) of city planners/developers over the smart city initiative case, of $\alpha$ denotes the learning rate of CBR, set to 0.1 for slowly regulating SV(SC). Then, for new adapted smart city initiative case, the survival value is based on Eq. (15):

$\mathrm{SV}(X)=\sum n i=1(X, \mathrm{SCC} i) * \mathrm{SR}(\mathrm{SC} i) / n$,

where $\mathrm{SC} i$ is the survival value of the similar case, $n$ is the number of smart city initiative cases contributing to the adaptation of $X, \mathrm{SC} i$ is $i$ th reference case and $\operatorname{Sim}(X, \mathrm{SC} i)$ is the retrieved solution similarity between $X$ and SC $i$. Then $\alpha$ is used as a weighing scale to balance city planners/developer's satisfaction and smart city case similarity in saving or retaining an adapted smart city initiative case, which is changed based on city planners/developers feedback or smart city initiative case similarity. Moreover, in the case retaining process if the reference smart city case solution has a higher user satisfaction (based on the pre-defined survival threshold $\triangle \mathrm{SV}$ (SCC) set by the smart city expert or developer) CBR directly retains the previous solution case.

\subsection{System development}

In developing the CBR recommender system, a class diagram is designed. A class diagram is a unified modelling language (UML) static structure modeling which displays the structure of a designed system based on how the defined classes, their elements, activities, as well as the relationships among them are connected. Accordingly, Fig. 9 shows the class diagram for the proposed CBR recommender system.

Figure 9 shows the class diagram of the proposed CBR recommender system which provides guidelines as recommendation guidelines to city planners/developers in developing a smart city towards attaining sustainability. As presented in Fig. 9, the class diagram comprises of six classes which are smart city experts, smart city dimensions, smart city best practice initiatives, city planners/developers, inquiry, and CBR knowledge base. Accordingly, the CBR smart city recommender system is developed for smart city planning development and deployed in XAMPP application run locally to test the system to ensure it is fully functional and meets the requirements to provide information on smart city dimensions. In addition, CBR recommender system is deployed to test the applicability of CBR technique for providing smart city initiative case recommendations. The CBR smart city recommender tool is also deployed to ensure that the smart city expert is able to add new cases of smart city initiatives to be utilized by city planners/developers as seen in Fig. 6. Accordingly, the CBR recommender system was implemented using hypertext preprocessor (PHP) and hypertext markup language (HTML) for interface design and MySQL for the CBR knowledge base development. Next, Fig. 10 shows the proof of concept for the system interfaces of the CBR recommender system.

Figure 10 depicts the proof of concept for CBR search, smart city dimensions, and associated initiatives. The top left interface of Fig. 10 shows the developed CBR advance search illustrating the proof of concept for CBR search employed by city planners/developers to retrieve smart city initiatives from the knowledge base in relation to smart city dimensions. Also, the top right interface in Fig. 10 depicts smart city dimensions, whereas the interface below in Fig. 10 shows the associated smart city initiatives with description on how city planners/developers can implement the selected smart city initiatives in their municipalities as suggested by Washburn et al. (2009) to depict the constituents of smart city initiatives. 


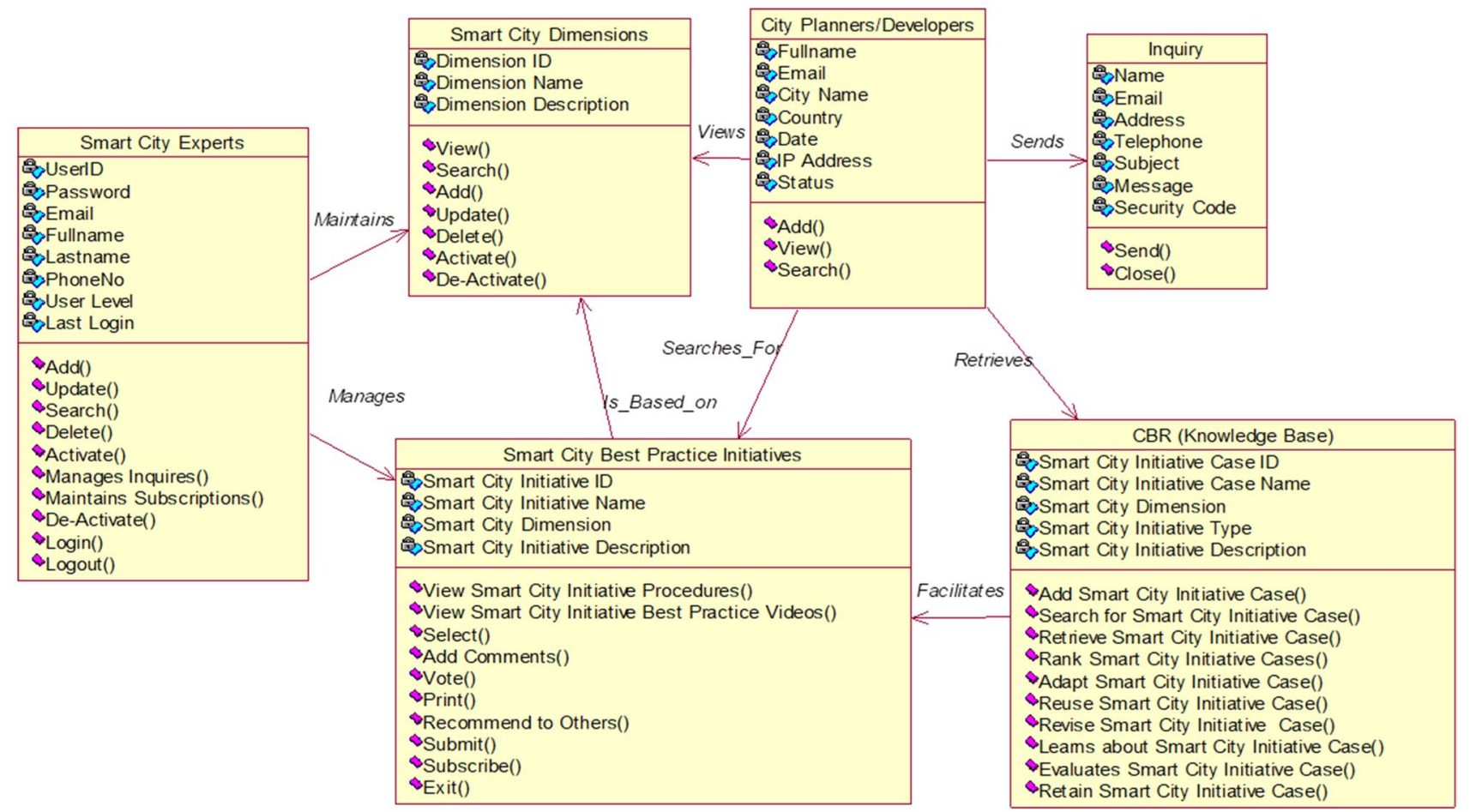

Fig. 9 Class diagram for the proposed CBR recommender system for smart city

\section{Research methodology}

This study adopts a quantitative research approach and data were collected using survey questionnaire. Although, this study is concerned with information retrieval, formal and quantitative evaluation of precision and relevance using known metrics such as normalized distance-based performance measure (NDPM), normalized discounted cumulative gain (NDCG), average distance measure (ADM), mean average precision (MAP), etc. was not employed, since this study is not employing experiments to evaluate the effectiveness of web search engine retrieval algorithms. Thus, these techniques are not applicable for this study instead, a survey questionnaire was employed for evaluation as used by prior recommender studies (Waqar et al. 2019; Iovine et al. 2020). The survey questions were designed to evaluate the applicability of the developed CBR recommender tool for smart city planning development to provide recommendations for city planners, developers and decision makers similar to prior studies Casino et al. (2017) and Anthony et al. (2018b). Therefore, the survey instrument questions and sources as seen in Table 4 are developed to measure recommendation content, recommendation presentation, system quality, information quality, service quality, CBR search, security and trust, and system support of the developed CBR recommender tool.
The survey questions are divided into two sections; section one consists of demographic characteristics of the respondents. The second part comprises of questions used to measure the applicability of the developed CBR recommender tool using a Likert scale with five response categories (1-5) was used where " 1 " indicates strongly disagree and "5" represents strongly agree. Statistical Package for Social Science (SPSS) version 23 is used for data analysis. Next, descriptive statistics was employed to describe the data collected to accurately characterize the items under observation within a specific sample (Anthony et al. 2018b). Descriptive statistics provides information about the overall representativeness of the sample, as well as the information necessary for other researchers to replicate the study (Cooper and Schindler 2008). In this research, mean and standard deviation score are used to measure the applicability of the recommender tool for smart city. Moreover, exploratory factor analysis (EFA) is used to identify the structure of the relationship between the questionnaire items and the respondents. EFA is based on the common factor model (Anthony Jnr et al. 2019). Besides, EFA is used when based on their magnitude (greater than $+0.30=$ minimum consideration level,$+0.40=$ more important and $+0.50=$ practically significant $)$ (Cooper and Schindler 2008).

EFA entails validity and reliability, thus validity refers to the degree in which an instrument such as questionnaire 


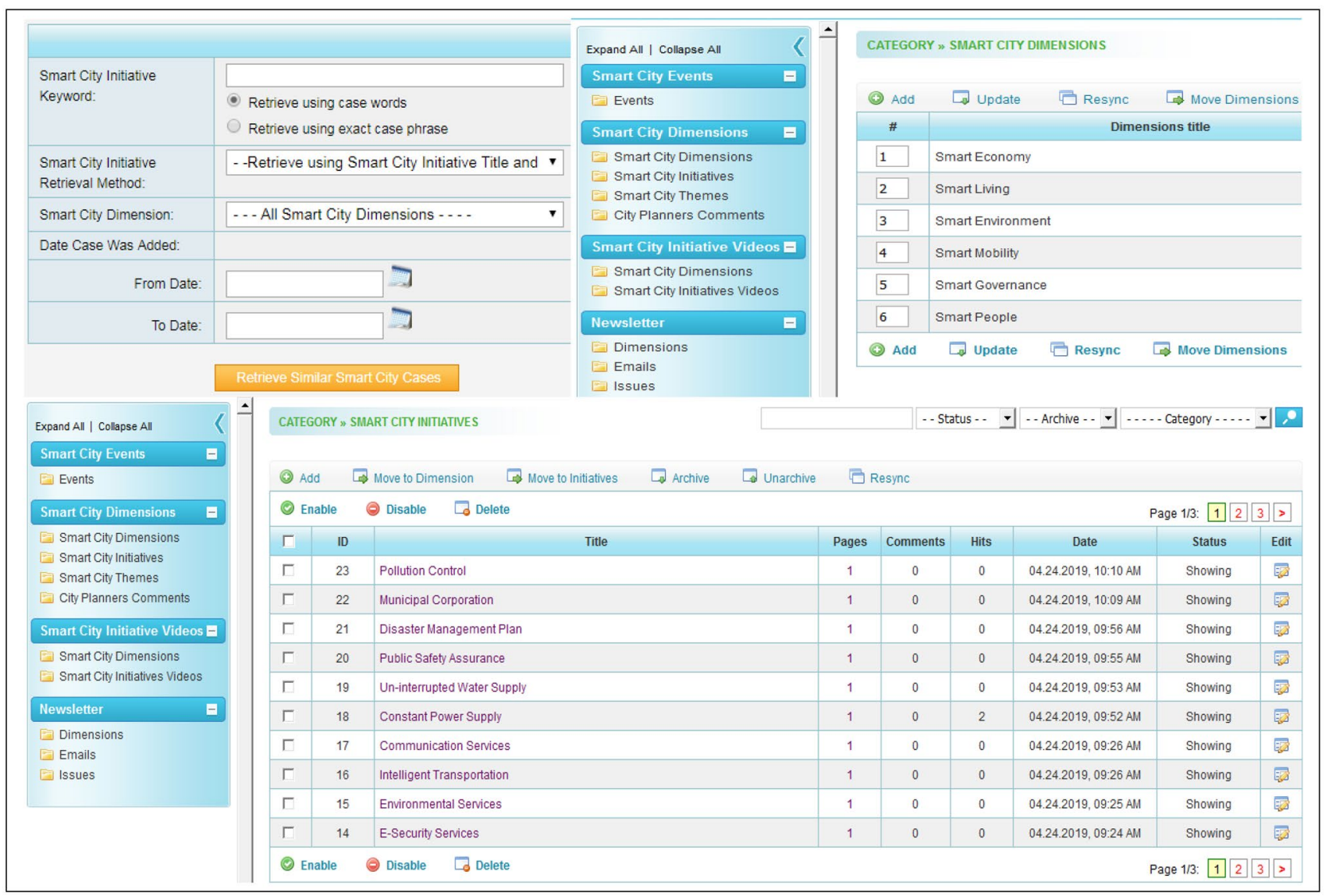

Fig. 10 Proof of concept for the developed CBR recommender system

measures what is intended to measure. In this study, validity is determined by correlation, exploratory factor analysis in SPSS by considering the Pearson's correlation $(r)$ value. Likewise, reliability refers to degree to which the measure of concept is stable or if the measurement procedure yields consistent results over extended time frame (Hair et al. 2016). The Cronbach's alpha is used to measure the internal consistency reliability coefficient and it ranges from 0 to 9 , where " $>0.9$ - excellent, $>0.8$ good, $>0.7$-acceptable, $>0.6$-questionable, $>0.5$ - poor and $<0.5$ - unacceptable" (Anthony Jr et al. 2018a).

\section{Results}

\subsection{Demographic data}

The demographic characteristics of the survey respondents are illustrated in Table 5.

Table 5 depicts the demographic data of the 115 survey respondents measured using ordinal scale. The results are presented in frequency and percentage.

\subsection{Descriptive analysis}

The descriptive analyses comprise of maximum, minimum, mean, standard deviation, skewness, and kurtosis values of recommendation content, recommendation presentation, system quality, information quality, service quality, CBR search, security, and trust, and system support of the developed CBR recommender system as presented in Table 6.

Table 6 depicts the descriptive statistics results of each questionnaire component used to test the applicability of the developed CBR recommender system in relation to how the tool provides recommendation to city planners/developers in adopting smart city initiatives. The items were all measured based on 5-point Likert scale ranging from strongly disagree as " 1 " and strongly agree as "5", where for the mean $1=$ not effective; 2 =barely effective; 3 =effective; $4=$ very effective; and $5=$ most effective as suggested by Anthony et al. (2018b). An unbalanced scale was employed as it helps to measure the perception of the respondents in relation to the applicability of the CBR recommender system without influencing their judgement in relation to the questionnaire items as compared to using a balance scale which may lead to bias of response from the respondents. Thus, results from 
Table 4 Questionnaire items

\begin{tabular}{|c|c|c|}
\hline Components & Items & References \\
\hline Recommendation content & $\begin{array}{l}\text { RC1-The system provides complete and up-to-date smart } \\
\text { city recommendations } \\
\text { RC2-The system provides sufficient smart city recom- } \\
\text { mendations } \\
\text { RC3-The smart city recommendation provided by the } \\
\text { system is effective } \\
\text { RC4-The system adequately meets my smart city recom- } \\
\text { mendations needs }\end{array}$ & Cyr (2013) and Anthony Jnr (2019) \\
\hline Recommendation presentation & $\begin{array}{l}\text { RP1-The system logically presents in-depth smart city } \\
\text { initiative recommendations } \\
\text { RP2-Smart city dimension recommendations provided } \\
\text { by the system are well organized } \\
\text { RP3- Recommendations from the knowledge base are } \\
\text { well structured and presented } \\
\text { RP4-The system takes less time to download and present } \\
\text { recommendations }\end{array}$ & Elling et al. (2012) and Anthony Jr et al. (2018a) \\
\hline System quality & $\begin{array}{l}\text { SQ1-I can easily navigate the system } \\
\text { SQ2-The system is easy to use and user friendly } \\
\text { SQ3-This system provides good navigation to recom- } \\
\text { mendation content } \\
\text { SQ4-The system design such as images, layout, and } \\
\text { colors are attractive } \\
\text { SQ5-The structure of the system is clearly presented }\end{array}$ & $\begin{array}{l}\text { Elling et al. (2012), Lee and Kozar (2012) and Cyr } \\
\text { (2013) }\end{array}$ \\
\hline Information quality & $\begin{array}{l}\text { IQ1-The system clearly directs me towards the needed } \\
\text { recommendation } \\
\text { IQ2-The links in the system direct me to the required } \\
\text { recommendation } \\
\text { IQ3-The system provides precise and relevant recom- } \\
\text { mendation } \\
\text { IQ4-The recommendations provided by the system is } \\
\text { appropriate and accurate }\end{array}$ & Cyr (2013), Anthony Jnr et al. (2019) \\
\hline Service quality & $\begin{array}{l}\text { SEQ1-The recommendations in the system are compre- } \\
\text { hensive and helpful } \\
\text { SEQ2-The language utilized in the system is complete } \\
\text { and clear to me } \\
\text { SEQ3-The recommendations presented by the system are } \\
\text { easy to understand } \\
\text { SEQ4-The layout design of system is appealing } \\
\text { SEQ5-All interfaces in the system are consistently } \\
\text { designed } \\
\text { SEQ6-The system structure is succinct and simple to use }\end{array}$ & $\begin{array}{l}\text { Elling et al. (2012), Lee and Kozar (2012) and Cyr } \\
\text { (2013) }\end{array}$ \\
\hline CBR search & $\begin{array}{l}\text { CR1-The CBR search helps to quickly retrieve the right } \\
\text { smart city recommendations } \\
\text { CR2-The CBR search on the system provide useful } \\
\text { smart city initiatives recommendations }\end{array}$ & Anthony et al. $(2018 \mathrm{a}, \mathrm{b})$ \\
\hline Security and trust & $\begin{array}{l}\text { ST1-The system possesses an acceptable level of secu- } \\
\text { rity for personal information } \\
\text { ST2-The system is stable to use } \\
\text { ST3-The smart city recommendations presented by this } \\
\text { system are trustworthy } \\
\text { ST4-I trust the system to keep my personal data safe }\end{array}$ & Elling et al. (2012) and Lee and Kozar (2012) \\
\hline System support & $\begin{array}{l}\text { SS1-The system is easy to navigate and locate smart city } \\
\text { recommendations } \\
\text { SS2-The system is flexible and provide help support } \\
\text { SS3-The system is easy to learn and remember how to } \\
\text { access web pages } \\
\text { SS4-The system requires less effort to use }\end{array}$ & Lee and Kozar (2012) and Cyr (2013) \\
\hline
\end{tabular}


Table 5 Demographic characteristic of survey respondents

\begin{tabular}{lllc}
\hline Profile & Options & Frequency & Percentage \\
\hline Gender & Male & 50 & 43.5 \\
Age & Female & 65 & 56.5 \\
& $<25$ & 1 & 0.90 \\
& $25-34$ & 41 & 35.7 \\
& $35-44$ & 56 & 48.7 \\
& $45-55$ & 16 & 13.9 \\
Educational qualification & $>55$ & 1 & 0.90 \\
& Diploma & 4 & 3.50 \\
& Bachelor's degree & 29 & 25.2 \\
& Master's degree & 43 & 37.4 \\
& Doctorate & 26 & 22.6 \\
& Professional certificate & 13 & 11.3 \\
Current job title & Sustainability professional & 44 & 38.3 \\
& City planner & 56 & 48.7 \\
& City developer & 2 & 1.70 \\
& ICT professional & 2 & 1.70 \\
& Smart city professional & 11 & 9.60 \\
& Others & 44 & 38.3 \\
\hline
\end{tabular}

Table 6 indicates that all mean values are greater than 2.5 suggesting that the respondents agreed that the developed system is applicable in providing recommendation on smart city initiatives.

Findings from the data suggest that the respondents perceived that the developed tool supports recommendation content with mean values ranging from 3.57, 3.53, 3.48, and 3.15. This result indicates that the system provides complete and sufficient up-to-date smart city recommendations that effectively and adequately meets smart city needs. Similarly, the results indicate that for recommendation presentation, the system presents logical, well-organized in-depth smart city initiative recommendations which take less time to be retrieved from the knowledgebase with mean scores of 3.26, 3.22, 3.17, and 3.15. The mean score for system quality ranges between $3.36,3.35,3.25,3.15$, and 3.12, suggesting that the system is easy to use, user friendly in navigating to information content which is clearly presented. Also, in assessing the system in terms of information quality, the results reveal that the system links clearly directs users to precise, appropriate, accurate, and relevant information on smart city initiatives with mean scores of 3.24, 3.21, 3.02, and 2.95.

Moreover, the results suggest that for service quality the system provides comprehensive recommendations in a comprehensive language which is easy to understand in a consistently appealing layout design structure which is succinct and simple to use with mean values of $3.58,3.32,3.27,3.20$, and 3.17. Also, with mean value of 3.68 and 3.30 the results further confirm that the CBR search helps to quickly retrieve correct smart city information which provides useful smart city initiatives recommendation. Additionally, for security and trust, the mean values are $3.47,3.42,3.31$, and 3.19 indicating that the respondents agree that the system is safe and stable to use and has an acceptable level of security which makes the system trustworthy in storing personal information. Lastly, the respondents confirmed that the system provides support in terms of easy navigation in locating recommendations, providing flexible help support, requires less effort to use, and easy to learn and recall in accessing information on smart city initiatives with mean values of 3.73, 3.69, 3.39, and 3.27.

Besides, standard deviation is lower than 1 for all measured components. The minimum value is 1 and maximum value is 5 . Besides, the data were also screened to confirm normality by checking the skewness and kurtosis values. The values of the skewness and kurtosis for the items were between the recommended cutoffs of 3.0 for skewness and 8.0 for kurtosis as recommended by Teo (2019).

\subsection{Exploratory factor analysis}

To measure the reliability and validity, the measured components were measured based on Cronbach's alpha " $a$ " which should be higher than 0.70 . Accordingly, results from Table 7 suggest that the reliability of all components is higher than 0.7 , hence revealing that the developed CBR recommender system is acceptable by the survey respondents and applicable for smart city recommendation. According to Anthony Jr et al. (2018a), the correlation coefficient ranges from $0.1-0.29=$ Weak, $0.30-0.49=$ Moderate and $0.50-1.0=$ Strong. Results from Table 7 shows the results of the validity in person correlation " $r$ " of the tool based on the measured components used to evaluate the system. 
Table 6 Descriptive analysis of applicability components

\begin{tabular}{|c|c|c|c|c|c|c|c|}
\hline Components & Items & Minimum & Maximum & Mean & Std. deviation & Skewness & Kurtosis \\
\hline \multirow[t]{4}{*}{ Recommendation content } & $\mathrm{RC} 1$ & 1 & 5 & 3.57 & 0.860 & 0.047 & 0.172 \\
\hline & $\mathrm{RC} 2$ & 1 & 5 & 3.48 & 0.902 & -0.153 & 0.581 \\
\hline & $\mathrm{RC} 3$ & 1 & 5 & 3.53 & 0.862 & 0.155 & 0.162 \\
\hline & $\mathrm{RC} 4$ & 1 & 5 & 3.15 & 1.019 & -0.303 & 0.263 \\
\hline \multirow[t]{4}{*}{ Recommendation presentation } & RP1 & 1 & 5 & 3.15 & 0.993 & -0.303 & 0.337 \\
\hline & $\mathrm{RP} 2$ & 1 & 5 & 3.26 & 0.965 & -0.130 & 0.499 \\
\hline & RP3 & 1 & 5 & 3.22 & 1.016 & -0.399 & 0.242 \\
\hline & RP4 & 1 & 5 & 3.17 & 1.037 & -0.213 & 0.298 \\
\hline \multirow[t]{5}{*}{ System quality } & SQ1 & 1 & 5 & 3.12 & 1.101 & -0.366 & -0.075 \\
\hline & SQ2 & 1 & 5 & 3.15 & 1.019 & -0.404 & 0.324 \\
\hline & SQ3 & 1 & 5 & 3.36 & 0.957 & -0.223 & 0.456 \\
\hline & SQ4 & 1 & 5 & 3.35 & 1.009 & -0.278 & 0.384 \\
\hline & SQ5 & 1 & 5 & 3.25 & 1.042 & -0.145 & 0.171 \\
\hline \multirow[t]{4}{*}{ Information quality } & IQ1 & 1 & 5 & 3.24 & 1.039 & -0.124 & 0.000 \\
\hline & IQ2 & 1 & 5 & 3.21 & 1.080 & -0.342 & 0.013 \\
\hline & IQ3 & 1 & 5 & 2.95 & 1.146 & -0.074 & -0.308 \\
\hline & IQ4 & 1 & 5 & 3.02 & 1.017 & -0.188 & 0.126 \\
\hline \multirow[t]{6}{*}{ Service quality } & SEQ1 & 1 & 5 & 3.20 & 1.045 & -0.130 & 0.027 \\
\hline & SEQ2 & 1 & 5 & 3.20 & 1.010 & -0.154 & 0.104 \\
\hline & SEQ3 & 1 & 5 & 3.17 & 0.973 & -0.398 & 0.517 \\
\hline & SEQ4 & 1 & 5 & 3.27 & 0.851 & -0.204 & 1.099 \\
\hline & SEQ5 & 1 & 5 & 3.32 & 0.894 & -0.009 & 0.542 \\
\hline & SEQ6 & 1 & 5 & 3.58 & 0.917 & 0.099 & -0.231 \\
\hline \multirow[t]{2}{*}{ CBR search } & CR1 & 1 & 5 & 3.68 & 0.904 & -0.040 & -0.173 \\
\hline & CR2 & 1 & 5 & 3.30 & 1.036 & -0.401 & 0.330 \\
\hline \multirow[t]{4}{*}{ Security and trust } & ST1 & 1 & 5 & 3.19 & 0.972 & -0.395 & 0.635 \\
\hline & ST2 & 1 & 5 & 3.42 & 0.927 & -0.056 & 0.331 \\
\hline & ST3 & 1 & 5 & 3.47 & 0.892 & 0.055 & 0.345 \\
\hline & ST4 & 1 & 5 & 3.31 & 1.029 & -0.220 & 0.164 \\
\hline \multirow[t]{4}{*}{ System support } & SS1 & 1 & 5 & 3.39 & 0.915 & -0.232 & 0.640 \\
\hline & $\mathrm{SS} 2$ & 1 & 5 & 3.27 & 1.003 & -0.248 & 0.271 \\
\hline & SS3 & 1 & 5 & 3.73 & 0.862 & 0.387 & -1.246 \\
\hline & SS4 & 1 & 5 & 3.69 & 0.831 & 0.365 & -0.987 \\
\hline
\end{tabular}

For mean, 1 = not effective; 2 = barely effective; $3=$ effective; $4=$ very effective; and $5=$ most effective

The recommended cutoff is 3.0 for skewness and 8.0 kurtosis as recommended by Teo (2019)

Furthermore, the questionnaire items were examined using factor analysis to assess the questionnaire items that influence respondents' opinion towards the applicability of the CBR recommender system as seen in Table 7. Therefore, the items factor loading, and total variance best describe the applicability criteria of the system are presented in Table 7 , where the factor loading higher than 0.30 is minimum consideration level, and 0.40 is more important and above 0.50 is practically significant (Hair et al. 2016). Respectively, results from Table 7 suggest that the item loadings are higher than or equal to 0.5 as recommended. Also, results for Kaiser-Meyer-Olkin (KMO) indicate that all components values are higher than 0.5 when $p$ is $=<0.05$ which is the requested benchmark as shown in Table 7. Where all $p$ values are $=0.000$ which suggest that all components are significant since $p$ values is less than 0.05 as recommended by Hair et al. (2016).

Additionally, the total variance which explains the percentage of variance for all components show that recommendation content has the strongest effect of 78.555 suggesting that the developed system is applicable in explaining $78.555 \%$. Next, system support has the lowest percentage of variance value of 0.568 which reveal that the implemented tool provides only $5.68 \%$ help to city planners/developers. Moreover, results from Table 7 suggest that recommendation content has the highest percentage of variance value 
Table 7 Exploratory factor analysis for the developed system

\begin{tabular}{|c|c|c|c|c|c|c|c|}
\hline Components & Items & $\begin{array}{l}\text { Cronbach's } \\
\text { alpha }(\alpha)\end{array}$ & $\begin{array}{l}\text { Pearson cor- } \\
\text { relation }(r)\end{array}$ & Factor loading & KMO & $\%$ of variance & $\begin{array}{l}\text { Bartlett's test } \\
\text { of sphericity ( } p \\
\text { value) }\end{array}$ \\
\hline \multirow[t]{4}{*}{ Recommendation content } & $\mathrm{RC} 1$ & 0.850 & 0.791 & 0.904 & & & \\
\hline & $\mathrm{RC} 2$ & 0.830 & 0.842 & 0.926 & 0.782 & 78.555 & 0.000 \\
\hline & $\mathrm{RC} 3$ & 0.814 & 0.891 & 0.957 & & & \\
\hline & $\mathrm{RC} 4$ & 0.941 & 0.566 & 0.712 & & & \\
\hline \multirow[t]{4}{*}{ Recommendation presentation } & RP1 & 0.913 & 0.748 & 0.732 & & & \\
\hline & $\mathrm{RP} 2$ & 0.881 & 0.843 & 0.839 & 0.821 & 8.087 & 0.000 \\
\hline & RP3 & 0.910 & 0.756 & 0.740 & & & \\
\hline & RP4 & 0.861 & 0.896 & 0.896 & & & \\
\hline \multirow[t]{5}{*}{ System quality } & SQ1 & 0.917 & 0.761 & 0.713 & & & \\
\hline & SQ2 & 0.915 & 0.763 & 0.714 & & & \\
\hline & SQ3 & 0.907 & 0.808 & 0.780 & 0.873 & 4.828 & 0.000 \\
\hline & SQ4 & 0.901 & 0.835 & 0.810 & & & \\
\hline & SQ5 & 0.897 & 0.857 & 0.838 & & & \\
\hline \multirow[t]{4}{*}{ Information quality } & IQ1 & 0.904 & 0.732 & 0.712 & & & \\
\hline & IQ2 & 0.884 & 0.793 & 0.784 & 0.758 & 3.245 & 0.000 \\
\hline & IQ3 & 0.878 & 0.810 & 0.812 & & & \\
\hline & IQ4 & 0.864 & 0.852 & 0.847 & & & \\
\hline \multirow[t]{6}{*}{ Service quality } & SEQ1 & 0.929 & 0.892 & 0.864 & & & \\
\hline & SEQ2 & 0.920 & 0.800 & 0.743 & & & \\
\hline & SEQ3 & 0.932 & 0.875 & 0.849 & & & \\
\hline & SEQ4 & 0.924 & 0.893 & 0.872 & 0.845 & 2.296 & 0.000 \\
\hline & SEQ5 & 0.921 & 0.655 & 0.557 & & & \\
\hline & SEQ6 & 0.948 & 0.892 & 0.864 & & & \\
\hline \multirow[t]{2}{*}{ CBR search } & CR1 & 0.913 & 0.623 & 0.759 & 0.500 & 1.375 & 0.000 \\
\hline & CR2 & 0.888 & 0.803 & 0.759 & & & \\
\hline \multirow[t]{4}{*}{ Security and trust } & ST1 & 0.896 & 0.750 & 0.675 & & & \\
\hline & $\mathrm{ST} 2$ & 0.893 & 0.768 & 0.704 & 0.752 & 1.045 & 0.000 \\
\hline & ST3 & 0.888 & 0.809 & 0.816 & & & \\
\hline & ST4 & 0.893 & 0.769 & 0.793 & & & \\
\hline \multirow[t]{4}{*}{ System support } & $\mathrm{SS} 1$ & 0.726 & 0.680 & 0.904 & & & \\
\hline & $\mathrm{SS} 2$ & 0.789 & 0.563 & 0.915 & 0.574 & 0.568 & 0.000 \\
\hline & SS3 & 0.753 & 0.626 & 0.954 & & & \\
\hline & SS4 & 0.755 & 0.625 & 0.955 & & & \\
\hline
\end{tabular}

Factor analysis $=>0.5$, Cronbach's alpha $=>0.7$, and $p$ value $=<0.05$ to be significant. For Kaiser-Meyer-Olkin (KMO) mediocre $(0.5-0.7)$, good (0.7-0.8), great (0.8-0.9), and superb (above 0.9). For Pearson correlation $(r)$, weak $=0.1-0.29$, moderate $=0.30-0.49$, and strong $=0.50-$ 1.0

of 78.555 , followed by recommendation presentation with percentage of variance value of 8.087 , and then system quality with values 4.828 . Moreover, information quality has a value of 3.245 and service quality has a value of 2.296 . Then, CBR search percentage of variance value is 1.375 , followed by security and trust of the system with 1.045. Lastly, system support service provided by the system is explained as 0.568 . Therefore, results of descriptive and exploratory factor analysis validate the applicability in verifying the reliability and validity of the implemented CBR recommender tool for making cities smarter.

\section{Discussion and implications}

With continuous increase in city inhabitants, the need to plan and implement smart city solutions for enhanced urban governance is becoming important. The term smart city is usually aligned to urban areas where ICT is utilized to support city development and enhance social needs of stakeholders, aiding to provide a sustainable exploitation of city resources and services to improve residents' quality of life. Smart city embodies a method that makes the best use of technological and human resources to achieve a sustainable environment. 
As such cities in the world are adopting systems to ease urbanization issues. Smart city utilizes digital technologies to enhance the quality, management, and governance of urban services (Khan et al. 2013). Therefore, safeguarding habitable conditions to be in line with increased worldwide municipal population increase requires a comprehensive knowledge of smart city dimensions. Likewise, based on the urgency regarding these issues, cities have started to implement smarter ways to govern city planning ( $\mathrm{Su}$ et al. 2011). But, due to high uncertainty, complexity, and subjectivity of smart city planning development, where tacit or expert knowledge is required (Yeh and Shi 1999), to provide information regarding smart city dimensions as generalized, explicit, and definite knowledge to be adopted by city planners/developers.

In line with findings from Su et al. (2011), there is need for availability of adequate information on the dimensions of smart city that is needed to be deployed in fostering sustainable smart city development. Similarly, there are fewer approaches that provide data to policy makers to help make decision on smart city dimensions preference (Gaur et al. 2015). Additionally, it is challenging for city planners/developers to retrieve and utilize knowledge for city development (Alrawhani et al. 2016). In addition, existing knowledge management approaches are more suitable for addressing routine problems but lack the ability of storing smart city initiatives which is needed by city planners/developers to generate inventive solutions (Yeh and Shi 1999). Besides, in the past, there has been little application of AI technique such as CBR for smart city development (Alrawhani et al. 2016).

Therefore, this article employs CBR as state-of-the-art AI technique to develop a smart city recommender system as a proof-of-the-concept. The developed system is potentially useful in urban planning as it addresses issues related to knowledge elicitation by referring to prior cases and providing city planner/developer with valuable insights in addressing future problems for strategic planning. Accordingly, this study depicts the potential of CBR technique for providing solutions to improve city sustainability and enhancing citizens' quality of life. CBR is one of the most successful AI technique that exploits knowledge-rich representation of the application domain. Essentially, CBR is a problem-solving technique that resolves new problem by first retrieving a previous, already addressed similar case, and then reused that case for addressing the new problem. Findings from this study have significant implications for smart sustainable city as the developed CBR recommender system utilizes a knowledge-based recommender approach during search for smart city initiatives which assists city planners/developers to find appropriate strategies required for making decision related to sustainable city development.
Practically, this paper presented a knowledge-based recommendation approach for a smart city management to improve information sharing among city planners/developers towards improving the quality of services offered for citizens. Furthermore, the CBR recommender system provides a set of suggested smart city initiatives retrieved from the case base by searching for dimension similar to that partially described by the city planner/developer who explicitly provides some keywords being searched for and the system searches the knowledge base for information that match the user requirements. The retrieval procedure is based on a similarity check that calculates the similarity of the case description to the data in the case base. A set of smart city initiatives is then retrieved from the case base and these suggestions are recommended to city planner/developer. If the user is not satisfied with the retrieved recommendations, he/ she can amend the search query and new recommendation cycle is executed. Accordingly, the case base becomes a knowledge base which documents the strategies for designing smart sustainable cities.

\section{Conclusion}

Smart city aims to develop a viable economy through the sustainable use of natural resources, investment in humans and social assets built on an infrastructure of modern communication and transportation to attain an equitable society, balanced economy, and cleaner environment. This article investigates smart city adoption by identifying the smart city dimensions to be adopted. This study employed CBR as a knowledge-based approach to develop CBR smart city architecture and contributed to the body of knowledge by implementing a CBR recommender system for smart city planning development. CBR approach is utilized for addressing new problems based on the reuse of prior successful solutions utilized in previous problems. The case solution for the prior problem is retained as case in the knowledge base where each case has a solution and description constituent which is stored in the knowledge base. The case description explains the issue, and the case solution describes the specification of the solution.

Accordingly, CBR was integrated to provide recommendations on the smart city dimensions to be adopted by city planners/developers in achieving a smart city towards a sustainable society. In conclusion, the developed CBR recommender system provides suggestions based on the identified smart city dimensions which comprise of smart economy, smart mobility, smart environment, smart people, smart living, and smart governance. The system was evaluated using survey questionnaire data from 115 respondents who are familiar with smart city practice to test the applicability of the CBR recommender system in providing support for 
smart city adoption practices. Furthermore, findings from descriptive and exploratory factor analysis confirmed that the CBR recommender system is applicable for providing recommendation to improve smart city practice for municipalities in becoming a sustainable society.

It is evident that all studies possess limitation(s) and this research is not an exception. Hence, case adaptation phase in the CBR cycle was not completely implemented. The adaptation phase in the CBR recommender system was only integrated based on static adaptation interface. In addition, data was collected from only 115 respondents, where the sample size is acceptable for empirical study; however more data are required to be collected to increase the validity and robustness of the statistical results. In addition, data was collected from smart city experts, city planner, city developers, sustainability experts, IT experts, and other experts in a single country only hence the results cannot be generalized to other countries. Accordingly, future work entails completely implementing case adaptation phase, so that retrieved cases can be adapted by the city planner/developed before use in addressing current problems. Furthermore, more data are to be collected from respondents from other location to improve the generalization of the result. Finally, as the deployment of CBR in urban development is still at an early stage, further research is required to improve the integration of other AI techniques for smart city development.

Acknowledgements Open Access funding provided by NTNU Norwegian University of Science and Technology (incl St. Olavs Hospital - Trondheim University Hospital). The author will like to thank the Editor-in-Chief of AI \& Society and anonymous reviewers for their helpful comments they provided during the rounds of review which greatly improved the quality of the manuscript.

Open Access This article is licensed under a Creative Commons Attribution 4.0 International License, which permits use, sharing, adaptation, distribution and reproduction in any medium or format, as long as you give appropriate credit to the original author(s) and the source, provide a link to the Creative Commons licence, and indicate if changes were made. The images or other third party material in this article are included in the article's Creative Commons licence, unless indicated otherwise in a credit line to the material. If material is not included in the article's Creative Commons licence and your intended use is not permitted by statutory regulation or exceeds the permitted use, you will need to obtain permission directly from the copyright holder. To view a copy of this licence, visit http://creativecommons.org/licenses/by/4.0/.

\section{Appendix}

See Table 8.

Table 8 List of equation, variable/symbol and definition

\begin{tabular}{|c|c|c|}
\hline Equations & Variable/symbol & Meaning/definition \\
\hline 1,2 & SCS & Overall smart city solution \\
\hline 1,2 & $c$ and $c^{\prime}$ & Case 1 and case $n$ \\
\hline 1,2 & $s$ and $s^{\prime}$ & Solution 1 and solution $n$ \\
\hline $1,2,9,10,11,15$ & $i$ & Smart city initiative \\
\hline 1,2 & $x i$ & Smart city initiative information \\
\hline $1,2,3,4,9,10,11,15$ & $n$ & Index number of smart city initiative \\
\hline 3 & $A 1 n * n$ & Total pairwise comparison weight comparison \\
\hline 3,4 & $A i j$ & Smart city initiative pair wise comparison of a case \\
\hline 3,4 & $j$ & Comparative significance criterion for case 1 \\
\hline 3,4 & $I$ & Comparative significance criterion for case 2 \\
\hline 4,5 & $\mathrm{GM} i$ & Geometric mean \\
\hline 4,5 & $w i$ & Relative smart city initiative case weight \\
\hline 5 & $\sum$ & Summation \\
\hline 6 & $\mathrm{SM}$ & String match for smart city initiative in knowledge base \\
\hline 6,13 & $\mathrm{SC}$ & Smart city case \\
\hline 6 & $E(x, y)$ & Levenshtein distance measures of similarity based on case distance \\
\hline $6,7,8,10,11$ & $D$ & Smart city dimensions \\
\hline 6 & $\mathrm{CI}$ & Current case \\
\hline $6,7,8$ & $\mathrm{SM}(\mathrm{SC})$ & Number of similarities in common between the new and existing case \\
\hline 6 & $x$ & Smart city initiatives 1 in the knowledge base \\
\hline 6 & $y$ & Smart city initiatives 2 in the knowledge base \\
\hline 6 & $\epsilon$ & Is an element of \\
\hline 6 & $\exists$ & There exists \\
\hline 7,8 & $t$ & Threshold used in the measure similarity among cases \\
\hline
\end{tabular}


Table 8 (continued)

\begin{tabular}{|c|c|c|}
\hline Equations & Variable/symbol & Meaning/definition \\
\hline 9 & $n$ & Returned list of most similar cases \\
\hline 9 & $X$ & Entails a context, \\
\hline 9 & $C$ & Every retrieved case \\
\hline $9,10,11$ & $c i$ & Attribute of case properties 1 \\
\hline $9,10,11$ & $X i$ & Attribute of case properties 2 \\
\hline 9 & $F$ & Fuzzified weighted Euclidean distance \\
\hline 10,11 & $\mathrm{SC} 1$ & Smart city initiative 1 \\
\hline 10,11 & $\mathrm{SC} 2$ & Smart city initiative 2 \\
\hline 10,11 & $W$ & Weighted values assigned by the smart city expert \\
\hline 12 & $\operatorname{ESC}(c)$ & Existence value \\
\hline 12 & SCI & Restored solution case \\
\hline 12 & $\Delta$ & Change \\
\hline 12 & $\mathrm{ESC}$ (new) & The combination previous and adapted version of the case \\
\hline 12 & ESC (old) & The previous version of the case \\
\hline 12 & $\Delta \mathrm{ESC}(\mathrm{SCI})$ & The adapted version of the case \\
\hline 13 & $\mathrm{SC}$ (new) & Adapted value of the case \\
\hline 13 & $\mathrm{SC}$ (old) & Initial survival degree value of a newly added case \\
\hline 13 & $\Delta \mathrm{SV}(\mathrm{SC})$ & Adopted value of the case \\
\hline 14 & Sat & Levels of satisfaction or degree of satisfaction \\
\hline 14 & SSC1 & First solution employed for smart city initiative \\
\hline 14 & $\mathrm{SSC} 2$ & Second solution employed for smart city initiative \\
\hline 14 & $\Delta \mathrm{SV}$ & Change in survival value \\
\hline 14 & $\Delta \mathrm{SR}(\mathrm{SCC})$ & Adapted retained version of case \\
\hline 14 & $A$ & Learning rate of $\mathrm{CBR}$ \\
\hline 15 & $\operatorname{SV}(X)$ & New adapted smart city initiative case survival value \\
\hline 15 & Sci & Is the survival value of the similar case \\
\hline 15 & $X$ & Number of smart city initiative cases contributing to adaptation \\
\hline
\end{tabular}

\section{References}

Abu-Issa A, Nawawreh H, Shreteh L, Salman Y, Hassouneh Y, Tumar I, Hussein M (2017) A smart city mobile application for multitype, proactive, and context-aware recommender system. In: International conference on engineering and technology (ICET), pp 1-5

Alrawhani EM, Basirona H, Sa' ayaa Z (2016) Real estate recommender system using case-based reasoning approach. J Telecommun Electron Comput Eng 8(2):177-182

Alyari F, Jafari Navimipour N (2018) Recommender systems: a systematic review of the state of the art literature and suggestions for future research. Kybernetes 47(5):985-1017

Anthony B (2020) Information flow analysis of a knowledge mappingbased system for University Alumni collaboration: a practical approach. J Knowl Econ. https://doi.org/10.1007/s13132-02000643-3

Anthony B, Majid MA, Romli A (2016) A case based reasoning decision support model for Green ITIS diffusion in collaborative enterprise. In: IEEE conference on open systems (ICOS). pp 1-6. https://doi.org/10.1109/ICOS.2016.7881979

Anthony B Jr, Abdul Majid M, Romli A (2018a) A collaborative agent based green IS practice assessment tool for environmental sustainability attainment in enterprise data centers. J Enterp Inf Manag 31(5):771-795
Anthony B, Abdul Majid M, Romli A (2018b) Heterogeneous agentenabled decision system for evaluating Green IT performance in industrial environments. J Decis Syst 27(1):37-62

Anthony B, Petersen SA, Ahlers D, Krogstie J, Livik K (2019) Big data-oriented energy prosumption service in smart community districts: a multi-case study perspective. Energy Inform 2(1):36

Anthony Jnr B (2019) Validating the usability attributes of AHP-software risk prioritization model using partial least square-structural equation modeling. J Sci Technol Policy Manag 10(2):404-430

Anthony Jnr B, Abdul Majid M, Romli A (2019) Emerging case oriented agents for sustaining educational institutions going green towards environmental responsibility. J Syst Inf Technol 21(2):1328-7265

Anthony Jnr B, Abbas Petersen S, Ahlers D, Krogstie J (2020) API deployment for big data management towards sustainable energy prosumption in smart cities-a layered architecture perspective. Int J Sustain Energ 39(3):263-289

Anthopoulos LG, Vakali A (2012) Urban planning and smart cities: interrelations and reciprocities. In: Álvarez F et al (eds) The future internet. FIA2012. Lecture notes in computer science, vol 7281. Springer, Berlin, Heidelberg

Badii C, Bellini P, Cenni D, Difino A, Nesi P, Paolucci M (2017) Analysis and assessment of a knowledge based smart city architecture providing service APIs. Future Gener Comput Syst 75:14-29 
Benfares C, El Idrissi, YEB, Amine A (2016) Smart city: recommendation of personalized services in patrimony tourism. In: 4th IEEE international colloquium on information science and technology (CiSt), pp 835-840

Benfares C, El Idrissi YEB, Abouabdellah A (2017) Recommendation semantic of services in smart city. In: Proceedings of the 2 nd international conference on big data, cloud and applications, pp $1-6$

Bokolo AJ, Petersen SA (2019) A smart city adoption model to improve sustainable living. Norsk konferanse for organisasjoners bruk av informasjonsteknologi

Borja J (2007) Counterpoint: Intelligent cities and innovative cities. Universitat Oberta de Catalunya (UOC) Pap E-J Knowl Soc 5:10-11

Casino F, Batista E, Patsakis C, Solanas A (2015) Context-aware recommender for smart health. In: First international smart cities conference (ISC2),pp 1-2

Casino F, Patsakis C, Batista E, Borràs F, Martínez-Ballesté A (2017) Healthy routes in the smart city: a context-aware mobile recommender. IEEE Softw 34(6):42-47

Chourabi H, Nam T, Walker S, Gil-Garcia JR, Mellouli S, Nahon K, Pardo TA, Scholl HJ (2012) Understanding smart cities: an integrative framework. In: 45th Hawaii international conference on system sciences. pp 2289-2297. https://doi.org/10.1109/HICSS .2012 .615

Cooper and Schindler (2008) Surveys in Social research, 5th edn. Crows Nest, Australia

Cortés-Cediel ME, Cantador I, Gil O (2017) Recommender systems for e-governance in smart cities: State of the art and research opportunities. In: Proceedings of the international workshop on recommender systems for citizens, pp 1-6

Cyr D (2013) Website design, trust and culture: an eight country investigation. Electron Commer Res Appl 12(6):373-385

David B, Yin C, Zhou Y, Xu T, Zhang B, Jin H, Chalon R (2012) SMART-CITY: Problematics, techniques and case studies. In: 8th international conference on computing technology and information management, pp 168-174

Deakin M (2012) Intelligent cities as smart providers: CoPs as organizations for developing integrated models of eGovernment Services. Innov Eur J Soc Sci Res 25(2):115-135

Di Martino S, Rossi S (2016) An architecture for a mobility recommender system in smart cities. Procedia Comput Sci 98:425-430

Elling S, Lentz L, de Jong M, Van den Bergh H (2012) Measuring the quality of governmental websites in a controlled versus an online setting with the 'Website Evaluation Questionnaire'. Gov Inf Q 29(3):383-393

Faieq S, Saidi R, El Ghazi H, Rahmani MD (2019) A context-aware recommendation-based system for service composition in smart environments. SOCA 13(4):341-355

Gaur A, Scotney B, Parr G, McClean S (2015) Smart city architecture and its applications based on IoT. Procedia Comput Sci 52:1089-1094

Giffinger R, Gudrun H (2010) Smart cities ranking: an effective instrument for the positioning of the cities? ACE Archit City Environ 4(12):7-26

Giffinger R, Fertner C, Kramar H, Kalasek R, Pichler-Milanović N, Meijers E (2007) Smart cities: ranking of European mediumsized cities. Centre of regional science (srf), Vienna University of Technology, Vienna, Austria. www.smart-cities.eu/download/ smart_cities_final_report.pdf. Accessed 10 Mar 2020

Habibzadeh H, Boggio-Dandry A, Qin Z, Soyata T, Kantarci B, Mouftah HT (2018) Soft sensing in smart cities: Handling 3Vs using recommender systems, machine intelligence, and data analytics. IEEE Commun Mag 56(2):78-86

Hair JF et al (2016) A primer on partial least squares structural equation modeling (PLS-SEM). Sage Publications, Thousand Oaks
Hoadjli A, Rezeg K (2019) A scalable mobile context-aware recommender system for a smart city administration. Int J Parallel Emerg Distrib Syst. https://doi.org/10.1080/17445760.2019.1626855

Hotea O, Groza A (2013) Reasoning on semantic sensor streams for smart city. In: Proceedings of the international conference on intelligent information systems, pp 1-4

Hu B, Patkos T, Chibani A, Amirat Y (2012) Rule-based context assessment in smart cities. In: Krötzsch M, Straccia U (eds) Web reasoning and rule systems. RR 2012. Lecture notes in computer science, vol 7497. Springer, Berlin, Heidelberg

Iovine A, Narducci F, Semeraro G (2020) Conversational recommender systems and natural language: a study through the ConveRSE framework. Decis Support Syst 131:113250

Jnr BA, Majid MA, Romli A (2018) A trivial approach for achieving smart city: a way forward towards a sustainable society. In: 21 st Saudi computer society national computer conference (NCC), pp 1-6. https://doi.org/10.1109/NCG.2018.8592999

Jnr BA, Majid MA, Romli A (2020a) A generic study on Green IT/IS practice development in collaborative enterprise: Insights from a developing country. J Eng Tech Manag 55:101555

Jnr BA, Petersen SA, Ahlers D, Krogstie J (2020b) Big data driven multi-tier architecture for electric mobility as a service in smart cities. Int J Energy Sect Manag. https://doi.org/10.1108/IJESM -08-2019-0001

Jr BA, Majid MA, Romli A (2017) Green information technology system practice for sustainable collaborative enterprise: a structural literature review. Int J Sustain Soc 9(3):242-272

Khan Z, Anjum A, Kiani SL (2013) Cloud based big data analytics for smart future cities. In: IEEE/ACM 6th international conference on utility and cloud computing, pp 381-386. https://doi.org/10.1109/ UCC. 2013.77

Khan Z, Dambruch J, Peters-Anders J, Sackl A, Strasser A, Fröhlich P, Soomro K (2017) Developing knowledge-based citizen participation platform to support Smart City decision making: the Smarticipate case study. Information 8(2):47

Khan A, Ahmad A, Rahman AU, Alkhalil A (2020) A mobile cloud framework for context-aware and portable recommender system for smart markets. In: Mehmood R, See S, Katib I, Chlamtac I (eds) Smart infrastructure and applications. EAI/Springer innovations in communication and computing. Springer, Cham

Laurini R (2013) Towards smart urban planning through knowledge infrastructure. In: The ninth international conference on advanced geographic information systems, applications, and services, pp 75-80

Lee HJ, Kim HS (2015) eHealth Recommendation service system using ontology and case-based reasoning. In: International conference on Smart City/SocialCom/SustainCom (SmartCity), pp 1108-1113. https://doi.org/10.1109/SmartCity.2015.217

Lee Y, Kozar KA (2012) Understanding of website usability: specifying and measuring constructs and their relationships. Decis Support Syst 52(2):450-463

Lorenzi F, Ricci F (2003) Case-based recommender systems: a unifying view. In: Mobasher B, Anand SS (eds) Intelligent techniques for web personalization. ITWP 2003. Lecture notes in computer science, vol 3169. Springer, Berlin, Heidelberg

Luberg A, Tammet T, Järv P (2011) Smart city: a rule-based tourist recommendation system. In: Law R, Fuchs M, Ricci F (eds) Information and communication technologies in tourism 2011. Springer, Vienna

Madkour M, Benhaddou D, Khalil N, Burriello M, Cline Jr RE (2015) Living campus: towards a context-aware energy efficient campus using weighted case based reasoning. In: Workshops at the twentyninth AAAI conference on artificial intelligence, pp 42-47

Mohanty SP, Choppali U, Kougianos E (2016) Everything you wanted to know about smart cities: the internet of things is the backbone. IEEE Consum Electron Mag 5(3):60-70 
Moreno MV, Terroso-Sáenz F, González-Vidal A, Valdés-Vela M, Skarmeta AF, Zamora MA, Chang V (2017) Applicability of big data techniques to smart cities deployments. IEEE Trans Ind Inf 13(2):800-809

Nam T, Pardo TA (2011) Smart city as urban innovation: Focusing on management, policy, and context. In: Proceedings of the 5th international conference on theory and practice of electronic governance, pp 185-194. https://doi.org/10.1145/20720 69.2072100

Negre E, Rosenthal-Sabroux C (2014) Recommendations to improve the smartness of a city. In: Dameri R, Rosenthal-Sabroux C (eds) Smart City. Progress in IS. Springer, Cham

Orłowski C, Ziółkowski A, Orłowski A, Kapłański P, Sitek T, Pokrzywnicki W (2016) Smart cities system design method based on case based reasoning. In: Nguyen N, Kowalczyk R, Orłowski C, Ziółkowski A (eds) Transactions on computational collective intelligence XXV. Lecture notes in computer science, vol 9990. Springer, Berlin, Heidelberg

Schank R, Abelson R (eds) (1977) Scripts, plans, goals and understanding. Lawrence Eribaum, Hillsdale

Su K, Li J, Fu H (2011) Smart city and the applications. In: International conference on electronics, communications and control (ICECC), pp 1028-1031. https://doi.org/10.1109/ICECC .2011 .6066743

Tahir Z, Malek JA (2016) Main criteria in the development of smart cities determined using analytical method. Plan Malays J 14(5):1-14

Teo T (2019) Students and Teachers' intention to use technology: assessing their measurement equivalence and structural invariance. J Educ Comput Res 57(1):201-225

UN D (2015) World urbanization prospects: the 2014 revision. United Nations Department of Economics and Social Affairs, Population Division, New York

Vázquez Salceda J, Álvarez Napagao S, Tejeda Gómez JA, Oliva Felipe LJ, Garcia Gasulla D, Gómez Sebastià I, Codina
Busquet V (2014) Making smart cities smarter using artificial intelligence techniques for smarter mobility. In: SMARTGREENS2014-3rd international conference on smart grids and green IT systems, pp 7-11

Waqar M, Majeed N, Dawood H, Daud A, Aljohani NR (2019) An adaptive doctor-recommender system. Behav Inf Technol 38(9):959-973

Washburn D, Sindhu U, Balaouras S, Dines RA, Hayes N, Nelson LE (2009) Helping CIOs understand "smart city" initiatives. Growth 17(2):1-17

Watson I (2001) Knowledge management and case-based reasoning: A perfect match? In: FLAIRS Conference, pp 118-122

Watson I, Gardingen D (1999) A distributed case-based reasoning application for engineering sales support. In: Proc. 16th Int Joint Conf onArtificial Intelligence (IJCAI-99), vol. 1. Morgan Kaufmann Publishers Inc., pp 600-605. ISBN 1-55860-613-0

Yavari A, Jayaraman PP, Georgakopoulos D (2016) Contextualised service delivery in the Internet of Things: parking recommender for smart cities. In: 3rd world forum on internet of things (WFiot), pp 454-459

Yeh AGO, Shi X (1999) Applying case-based reasoning to urban planning: a new planning-support system tool. Environ Plan B Plan Des 26(1):101-115

Zare A, Motadel MR, Jalali A (2019) Presenting a hybrid model in social networks recommendation system architecture development. In: AI \& SOCIETY, pp 1-15. https://doi.org/10.1007/s0014 6-019-00893-z

Zhitomirsky-Geffet M, Zadok A (2018) Risk analysis and prediction in welfare institutions using a recommender system. AI Soc 33(4):511-525

Publisher's Note Springer Nature remains neutral with regard to jurisdictional claims in published maps and institutional affiliations. 